Journal for ImmunoTherapy of Cancer

\title{
JAK and mTOR inhibitors prevent cytokine release while retaining $T$ cell bispecific antibody in vivo efficacy
}

Gabrielle Leclercq (D) , ${ }^{1,2}$ Hélène Haegel, ${ }^{1}$ Alberto Toso, ${ }^{3}$ Tina Zimmermann, ${ }^{3}$ Luke Green, ${ }^{3}$ Nathalie Steinhoff, ${ }^{1}$ Johannes Sam, ${ }^{1}$ Vesna Pulko, ${ }^{1}$ Anneliese Schneider, ${ }^{1}$ Anna Maria Giusti, ${ }^{1}$ John Challier, ${ }^{1}$ Anne Freimoser-Grundschober, ${ }^{1}$ Laurent Larivière, ${ }^{4}$ Alex Odermatt (iD , ${ }^{2}$ Martin Stern, ${ }^{1}$ Pablo Umana, ${ }^{1}$ Marina Bacac, ${ }^{1}$ Christian Klein (1) ${ }^{1}$

To cite: Leclercq G, Haegel $\mathrm{H}$, Toso A, et al. JAK and mTOR inhibitors prevent cytokine release while retaining $T$ cell bispecific antibody in vivo efficacy. Journal for ImmunoTherapy of Cancer 2022;10:e003766. doi:10.1136/ jitc-2021-003766

- Additional supplemental material is published online only. To view, please visit the journal online (http://dx.doi.org/10. 1136/jitc-2021-003766).

Accepted 11 December 2021

Check for updates

(c) Author(s) (or their employer(s)) 2022. Re-use permitted under CC BY-NC. No commercial re-use. See rights and permissions. Published by BMJ.

${ }^{1}$ Roche Pharmaceutical Research and Early Development, Roche Innovation Center Zurich, Schlieren, Switzerland

${ }^{2}$ Department of Pharmaceutical Sciences, Division Molecular and Systems Toxicology, University of Basel, Basel, Switzerland

${ }^{3}$ Roche Pharmaceutical

Research and Early

Development, Roche Innovation Center Basel, Basel, Switzerland ${ }^{4}$ Roche Pharmaceutical

Research and Early

Development, Roche Innovation Center Munich, Penzberg, Germany

Correspondence to

Gabrielle Leclercq;

gabrielle.leclercq@roche.com

\section{ABSTRACT}

Background T cell engaging therapies, like chimeric antigen receptor $T$ cells and $T$ cell bispecific antibodies (TCBs), efficiently redirect T cells towards tumor cells, facilitating the formation of a cytotoxic synapse and resulting in subsequent tumor cell killing, a process that is accompanied by the release of cytokines. Despite their promising efficacy in the clinic, treatment with TCBs is associated with a risk of cytokine release syndrome (CRS). The aim of this study was to identify small molecules able to mitigate cytokine release while retaining T cellmediated tumor killing.

Methods By screening a library of 52 Food and Drug Administration approved kinase inhibitors for their impact on T cell proliferation and cytokine release after CD3 stimulation, we identified mTOR, JAK and Src kinases inhibitors as potential candidates to modulate TCBmediated cytokine release at pharmacologically active doses. Using an in vitro model of target cell killing by human peripheral blood mononuclear cells, we assessed the effects of mTOR, JAK and Src kinase inhibitors combined with 2+1T cell bispecific antibodies (TCBs) including CEA-TCB and CD19-TCB on T cell activation, proliferation and target cell killing measured by flow cytometry and cytokine release measured by Luminex. The combination of mTOR, JAK and Src kinase inhibitors together with CD19-TCB was evaluated in vivo in nontumor bearing stem cell humanized NSG mice in terms of $B$ cell depletion and in a lymphoma patient-derived xenograft (PDX) model in humanized NSG mice in terms of antitumor efficacy.

Results The effect of Src inhibitors differed from those of mTOR and JAK inhibitors with the suppression of CD19TCB-induced tumor cell lysis in vitro, whereas mTOR and JAK inhibitors primarily affected TCB-mediated cytokine release. Importantly, we confirmed in vivo that Src, JAK and mTOR inhibitors strongly reduced CD19-TCB-induced cytokine release. In humanized NSG mice, continuous treatment with a Src inhibitor prevented CD19-TCBmediated $B$ cell depletion in contrast to $\mathrm{mTOR}$ and JAK inhibitors, which retained CD19-TCB efficacy. Ultimately, transient treatment with Src, mTOR and JAK inhibitors minimally interfered with antitumor efficacy in a lymphoma PDX model.
Conclusions Taken together, these data support further evaluation of the use of Src, JAK and mTOR inhibitors as prophylactic treatment to prevent occurrence of CRS.

\section{BACKGROUND}

$\mathrm{T}$ cell engaging bispecific antibodies have raised major interest for the treatment of hematological and solid tumors. ${ }^{1-3}$ We have developed $\mathrm{T}$ cell bispecific antibodies (TCBs), for example, cibisatamab $(\text { CEA-TCB })^{45}$ or glofitamab (CD20-TCB), ${ }^{6}$ harboring a $2+1$ format with one binder to the CD3e chain and two binders to specific tumor antigens (figure 1A). Crosslinking of CD3 with tumor antigens triggers $\mathrm{T}$ cell activation and proliferation, cytokine release and tumor cell killing. ${ }^{7-11}$ In contrast to chimeric antigen receptor (CAR) $\mathrm{T}$ cells, TCBs represent an 'off the shelf' alternative to recruit $\mathrm{T}$ cells for tumor killing. 71213 Their Fc region is engineered with P329G LALA mutations preventing Fc $\gamma \mathrm{R}$ signaling pathways and enabling a longer half-life than Fv-based formats such as BiTE (Bi-specific T-cell engagers) antibodies. ${ }^{14}$ Treatment with TCBs can be associated with adverse events related to their mode-of-action such as the cytokine release syndrome (CRS), which is due to on-target activity. ${ }^{16} 17$ This complex clinical syndrome featured by fever and hypotension and/or hypoxia is hardly predictable. ${ }^{18}$ The main driver of CRS is a strong release of pro-inflammatory cytokines such as tumor necrosis factor (TNF)- $\alpha$ and interferon (IFN)- $\gamma$ (produced by $\mathrm{T}$ cells $)^{19}$ and TNF- $\alpha$, interleukin (IL) $-1 \beta$ and IL-6 (produced by myeloid cells). ${ }^{20-23}$ The symptoms of CRS can vary from mild to severe, and are classified in different grades. ${ }^{24} \mathrm{CRS}$ can be managed with glucocorticoids and/or anti-IL-6/R treatment such as tocilizumab or 
siltuximab. ${ }^{192526}$ If symptoms are not resolved, patients receive supportive care to stabilize blood pressure and oxygen saturation (eg, administration of vasopressors or oxygen). Despite the broad use of prophylactic glucocorticoids and step-up-dosing approaches to decrease CRS incidence and severity in the clinic, this complication remains the major dose-limiting toxicity associated with $\mathrm{T}$ cell engaging therapies. There is a continued need to develop alternative treatments with the goal to improve CRS management and to reduce patient hospitalization, ideally through prophylactic treatments to prevent or reduce the occurrence and severity of CRS. To identify potential candidates that inhibit both $\mathrm{T}$ cell proliferation and cytokine release while retaining $\mathrm{T}$ cell-mediated tumor killing, we screened 52 Food and Drug Administration (FDA)-approved tyrosine kinase inhibitors on CD3-stimulated $\mathrm{T}$ cells, mimicking TCB stimulation (online supplemental file 2). ${ }^{27}$ We selected JAK, mTOR, Src and MEK inhibitors as potent candidates to exert control over $\mathrm{T}$ cell proliferation and cytokine release. Using an in vitro model of target cell killing by human peripheral blood mononuclear cells (PBMCs), we tested the effect of mTOR, JAK and Src inhibitors on CD19TCB-induced cytokine release, $\mathrm{T}$ cell cytotoxicity and activation. In line with previous reports for CAR-T cells, the Src inhibitor dasatinib was found to fully switch-off CD19-TCB-induced $\mathrm{T}$ cell functionality. ${ }^{28-31}$ In contrast, mTOR inhibitors (temsirolimus, sirolimus and everolimus) and JAK inhibitors (ruxolitinib, baricitinib, and tofacitinib) were found to prevent CD19-TCB-induced cytokine release while not blocking TCB-mediated tumor cell killing at pharmacologically relevant doses. In vivo, mTOR and JAK inhibitors prevented cytokine release in humanized NSG mice treated with CD19-TCB, while not impairing $\mathrm{B}$ cell depletion. In lymphoma patient-derived xenograft (PDX)-bearing humanized NSG mice, transient treatment with kinase inhibitors inhibited cytokine release but did not impair CD19-TCB antitumor efficacy. The use of mTOR or JAK inhibitors therefore represents a promising strategy to prevent CRS on TCB treatment.

\section{MATERIAL AND METHODS \\ Kinase inhibitors and antibodies}

CEA-TCB (cibisatamab) and CD19-TCB were produced internally in the $2+1 \mathrm{TCB}$ format previously described (Bacac et al CCR 2016 for CEA-TCB). Dasatinib (S1021), ponatinib (S1490), bosutinib (S1014), sirolimus (S1039), temsirolimus (S1044), everolimus (S1120), ruxolitinib (S1378), baricitinib (S2851), fedratinib (S2736), tofacitinib (S2789), trametinib (S2673), dexamethasone (S1322) were purchased from Selleckchem. Methylprednisolone was purchased from Pfizer. The compounds from the library used in the screen were produced internally or purchased from Selleckchem, LC Laboratories, Ambeed or Apollo Scientific.

\section{Cell culture}

The SU-DHL-8 cell line is a human large cell lymphoma cell line (American Type Culture Collection (ATCC) catalog number CRL-2961). The NALM-6 cell line is an acute lymphoblastic leukemia cell line (ATCC CRL3273). SU-DHL-8 and NALM-6 cells were cultured in RPMI GlutaMAX (61870036, Gibco) containing 10\% fetal bovine serum (FBS) (26140079, Gibco) and split every 3-4days (to 0.8 million cells $/ \mathrm{mL}$ ) or on the day prior the assay. SU-DHL-8 and NALM- 6 cell lines provided from ATCC are routinely authenticated by short tandem repeat profiling prior to delivery. The diffuse large B cell lymphoma PDX was obtained from a patient who relapsed after R-CHOP treatment, and purchased from the Charles University in Prague. For in vitro use, the cells were thawed on the day of the assay and cultured in RPMI GlutaMAX (61870036, Gibco) containing 10\% FBS (26140079, Gibco). For in vivo use, the cells were thawed, counted and suspended in a 50:50 mix of RPMI (1530586, Gibco) and Matrigel (354234, Corning).

\section{PBMCs and pan-T cells isolation}

Peripheral blood mononuclear cells (PBMCs) were isolated from buffy coats donated by healthy volunteers (blood donation center in Zürich, in accordance with the Declaration of Helsinki) by Ficoll density gradient. T cells were isolated from fresh human PBMCs by negative magnetic isolation using the pan $\mathrm{T}$ cell isolation kit from Miltenyi Biotec (130-096-535). Before the assay, T cells and fresh or thawed PBMCs were counted and adjusted to $4.0 \times 10^{6} / \mathrm{mL}$ in assay medium. $50 \mu \mathrm{L}$ of the cell suspension were transferred to the wells of the assay plates, corresponding to 200,000 cells/well. For the proliferation assay, T cells were previously stained with the Cell Trace Violet (CTV) dye (Thermo Fisher, C34557) (5 $\mathrm{MM}, 20 \mathrm{~min}$ at room temperature (RT)).

\section{In vitro killing assays}

NALM-6, SU-DHL-8 or lymphoma PDX were labeled with

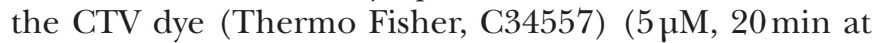
RT). 20,000 NALM-6, SU-DHL-8 or lymphoma PDX cells were transferred into each well $(100 \mu \mathrm{L})$ followed by 200,000 effector cells/well $(50 \mu \mathrm{L})$ to obtain a final effector:target cell (E:T) ratio of 10:1, respectively. The kinase inhibitors $(10 \mu \mathrm{L})$ followed by the antibody solutions $(50 \mu \mathrm{L})$ were then added. The assay plates were covered with lids, and placed in the incubator at $37^{\circ} \mathrm{C}, 5 \%$ carbon dioxide.

\section{Flow cytometry}

At assay endpoint, PBMCs were stained with the antibodies to CD4 (FITC, 317408, Biolegend), CD8 (BV605, 344742, Biolegend), CD25 (BUV395, 564034, BD), CD69 (PE, 310306, Biolegend), TIM3 (BV785, 345031 Biolegend), PD1 (BUV737, 565299, BD), LAG3 (APC, 369211, Biolegend) and Live Dead NIR (Thermo Fisher, L34975) in fluorescence-activated cell sorting (FACS) buffer $\left(30 \mathrm{~min}, 4^{\circ} \mathrm{C}\right)$. Cells were then washed twice in 
A

2:1 TCB

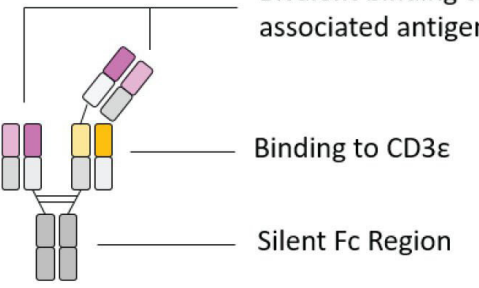

B

52 FDA approved drugs

1000,100 and $10 \mathrm{nM}$

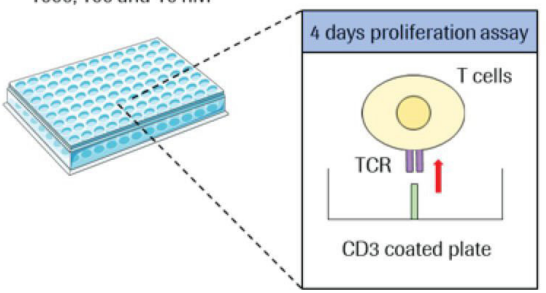

C

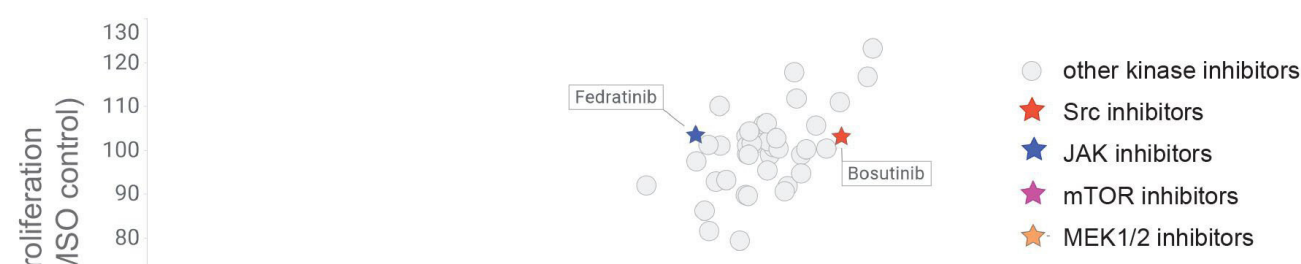

D

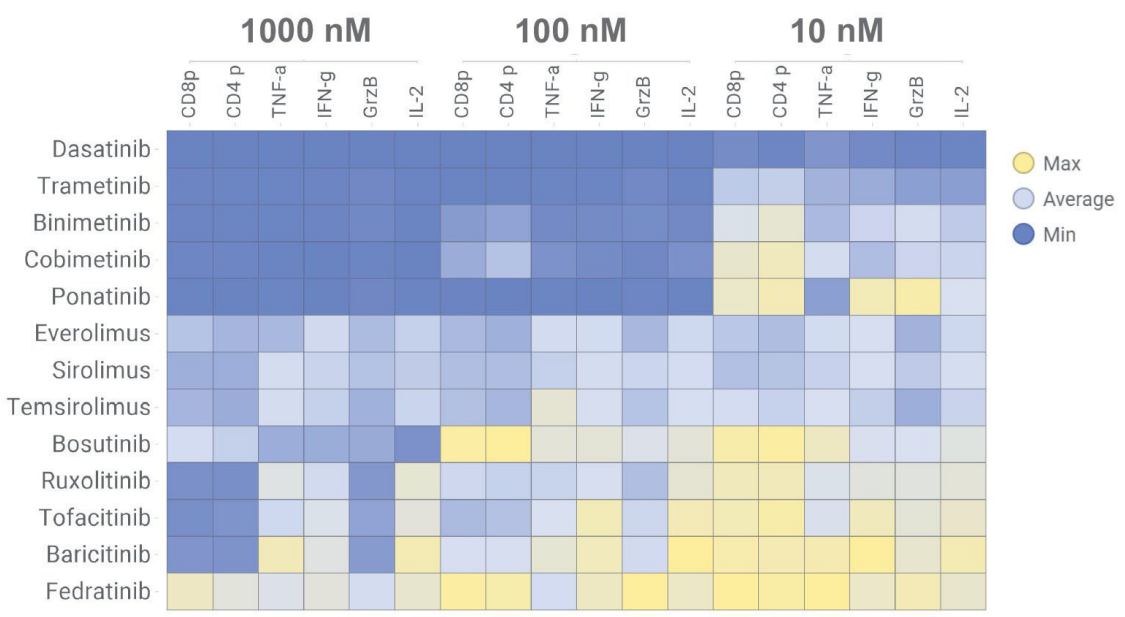

Figure 1 High throughput screening of 52 FDA-approved kinase inhibitor to identify candidates reducing TCB-induced T cell proliferation and cytokine release. (A) TCBs are fully humanized IgG1 antibodies providing bivalent binding to the tumor associated antigen and monovalent binding to the CD3 $\varepsilon$ of T-cell receptor on T cells ( $2+1$ format). (B) CTV-labeled pan T cells were stimulated on CD3 coated plate in the absence and presence of 10, 100 and $1000 \mathrm{nM}$ of each kinase inhibitor to mimic the TCB stimulation. (C) The dilution peaks of the CTV dye were measured by flow cytometry at 96 hours to evaluate the effect of the different kinase inhibitors on $\mathrm{CD}^{+}$and $\mathrm{CD}^{+} \mathrm{T}$ cell proliferation. The proliferation of $\mathrm{CD} 4^{+}$and $\mathrm{CD} 8^{+}$cells was normalized to proliferation of untreated T cells (DMSO control). mTOR, JAK, Src and MEK inhibitors were identified as hits of the screen. (D) The effects of escalating concentrations of the selected mTOR, JAK, Src and MEK inhibitor candidates on TNF- $\alpha$, IL-2, granzyme-B (GrzB), IFN- $\gamma$ and CD4+ (CD4 p) and CD8+ (CD8 p) proliferation are depicted in a heat map. The levels of TNF- $\alpha$, IL-2, GrzB and IFN- $\gamma$ were measured in the supernatants by CBA (24 hours) and normalized to untreated T cells. Median of technical triplicates, one donor. CBA, cytometric bead array; CTV, cell trace violet; DMSO, dimethyl sulfoxide; FDA, Food and Drug Administration; IFN, interferon; IL, interleukin; TCB, T cell bispecific antibody; TCR, T cell receptor; TNF, tumor necrosis factor. 
FACS buffer and re-suspended in $100 \mu \mathrm{L} /$ well FACS buffer for analysis. Killing of CTV-labeled tumor cells was measured by gating of dead NIR-positive cells among CTV positive tumor cells. Proliferation of CTV-labeled T cells was assessed by dilution of the CTV dye.

To measure B cell count in the blood, $25 \mu \mathrm{L}$ of blood was lysed twice using BD Pharm Lyse buffer (555899, BD) $(200 \mu \mathrm{L}, 10 \mathrm{~min}, \mathrm{RT})$. To measure B cell count in the spleen, spleens were processed, lysed with BD Pharm Lyse buffer (555899, BD) (2 mL, $10 \mathrm{~min}, \mathrm{RT}$ ) and cells were counted and suspended uniformly. Cells were then stained with the following the antibodies to CD45 (Alexa 700, 304119, Biolegend), CD20 (APC, 302309, Biolegend) and Live Dead NIR (L10119, Thermo Fisher) in FACS buffer $\left(30 \mathrm{~min}, 4^{\circ} \mathrm{C}\right)$. Cells were then washed twice in FACS buffer and re-suspended in $100 \mu \mathrm{L} /$ well FACS buffer for analysis. The acquisition of samples was performed using high throughput screening plate reader connected to a BD Fortessa Flow cytometer and the DIVA Software.

\section{Cytokine analysis}

Cytokines were analyzed in the culture supernatant or mouse serum samples (stored at $-80^{\circ} \mathrm{C}$ ) by Luminex using a human 8 plex assay kit (Bio-Rad) with additional IL-1 $\beta$ and monocyte chemoattractant protein-1 (MCP-1) beads, or human 23/40 plex assay kit (Bio-Rad). Prediluted supernatants/serum were incubated with beads in a 96-well filter plate ( 1 hour, $800 \mathrm{rpm}$, RT, no light). The plate was washed twice using a vacuum manifold and the detection antibodies solution was added ( 1 hour, $800 \mathrm{rpm}$, $\mathrm{RT}$, no light). The plate was vacuumed and washed twice and the streptavidin solution was added $(30 \mathrm{~min}, 800 \mathrm{rpm}$, RT, no light). The plate was vacuumed and washed twice and the samples were re-suspended in assay buffer. The sample acquisition was conducted using the Luminex equipment from Bio-Rad.

\section{In vivo studies in mice}

Humanized NSG mice were ordered from the Jackson Laboratory. The Institutional Animal Care and Use Committee of RICZ and the Cantonal Veterinary Office of Zurich approved the study protocol (license ZH225-17) in accordance with the Swiss Animal Protection Law. All the experiments were performed according to committed guidelines (GV-Solas; Felasa; TierschG) and under the AALAC accreditation. One day before treatment, humanized NSG mice were randomized based on their $\mathrm{T}$ cell counts into groups of three to four mice in the non-tumor bearing mouse study, or based on their tumor volumes into groups of seven to eight mice in the tumor-bearing mouse study. Blood was collected by tail-vein bleeding or by terminal retro-orbital bleeding. Tumor volumes were calculated from caliper measurements conducted 2-3 times per week. CD19-TCB $(0.5 \mathrm{mg} / \mathrm{kg})$, or vehicle were administered intravenously and kinase inhibitors as well as dexamethasone and methylprednisolone were given orally (p.o.). In both studies, mice treated with kinase inhibitors, methylprednisolone or dexamethasone 1 hour before and 6-7hours after the first treatment with CD19-TCB on day 0 . On day 1 and day 2, the Src inhibitors and JAK inhibitors were given twice per day and the mTOR inhibitors, methylprednisolone or dexamethasone were given once per day. In the PDX-bearing mouse study, humanized NSG mice received a total of four cycles of CD19-TCB (one treatment/week). 1 hour prior the second to last TCB treatment, mice were also treated with the lowest dose of the compounds. The doses of the different compound tested were the following: mTOR inhibitors: $5 \mathrm{mg} / \mathrm{kg}$, JAK inhibitors: $30 \mathrm{mg} / \mathrm{kg}$, Src inhibitor: 20 or $50 \mathrm{mg} / \mathrm{kg}$, dexamethasone: two times $1 \mathrm{mg} / \mathrm{kg}$ (day 0$), 0.5 \mathrm{mg} / \mathrm{kg}$ (day 1$), 0.25 \mathrm{mg} / \mathrm{kg}$, (day 2 and other) methylprednisolone: two times $10 \mathrm{mg} / \mathrm{kg}$ (day 0$), 5 \mathrm{mg}$ / $\mathrm{kg}$ (day 1), $2.5 \mathrm{mg} / \mathrm{kg}$ (day 2 and other).

\section{Histology analysis}

In the lymphoma PDX study, the tumor samples were harvested, fixed in 10\% formalin (Sigma, Germany) and later processed for FFPET (VIP6 Sakura, Japan). Four $\mu \mathrm{m}$ paraffin sections were subsequently cut with a microtome (Leica RM2235, Germany). H\&E staining was performed in automated Leica system (Leica ST5010) following the manufacturer's instructions. Immunohistochemistry was performed with an anti-human CD3 antibody (clone SP7, $\mathrm{d}=1 / 100$, Diagnostic Biosystem) in the Leica autostainer (Leica Bond RX, Germany). Sections were counterstained with hematoxylin and slides were scanned using Nanozoomer scanner (Hamamatsu, Japan). CD3 T cells were quantified using the Visiopharm software.

\section{Data analysis}

Flow cytometry data were analyzed using FlowJo V.10. Cytokine data were analyzed using the Bio-Plex software. The graphs and statistical analysis were generated with GraphPad Prism 8 or Tibco Spotfire. For dose-titration curves, areas under the curve (AUC) were calculated and used for statistical comparison and EC50 values were calculated by non-linear regression using the variable slope methods with four parameters. Data are shown as means with SD or SEM or as individual curves. The statistical tests used are indicated in the figure legends for each experiment.

Additional methods are described in the online supplemental material. The graphical abstract and figure $4 \mathrm{~A}$ were made with BioRender.com.

\section{RESULTS}

A small molecule screening of 52 FDA-approved kinase inhibitors identifies mTOR, JAK, MEK and Src kinase inhibitors as potential candidates to pause TCB-induced T cell proliferation

To identify families of kinase inhibitors that could potentially prevent $\mathrm{T}$ cell proliferation and cytokine release following CD3 stimulation, we screened a library of 52 FDA-approved kinase inhibitors at three different 
concentrations: 1000, 100 and 10 nM (figure 1A,B). CTVlabeled $\mathrm{T}$ cells were stimulated on CD3-coated plates in the presence and absence of the kinase inhibitors (figure 1B). At 96 hours, the dilution of the CTV dye was measured by flow cytometry as a readout for $\mathrm{CD}^{+}$and $\mathrm{CD}^{+} \mathrm{T}$ cell proliferation. As a result, mTOR, JAK, Src and MEK inhibitors strongly reduced $\mathrm{CD} 4^{+}$and $\mathrm{CD} 8^{+} \mathrm{T}$ cell proliferation when used at a concentration of $100 \mathrm{nM}$ (figure 1C,D and online supplemental figure S1A). In line with findings on $\mathrm{T}$ cell proliferation, the Src, MEK and mTOR inhibitors dose-dependently reduced T-cell derived cytokine as well as Granzyme B secretion, with the exception of the JAK inhibitors (figure 1D, online supplemental figure S1B). The screening of 52 FDA-approved kinase inhibitors enabled to select JAK inhibitors (ruxolitinib, baricitinib and tofacitinib), mTOR inhibitors (sirolimus, everolimus and temsirolimus), MEK inhibitors (trametinib, cobimetinib and binimetinib) and Src inhibitors (dasatinib and ponatinib) as potential drugs to fine tune TCB-induced T cell proliferation and cytokine release (figure 1C). We also considered the less potent Src inhibitor bosutinib and JAK inhibitor fedratinib, which inhibited $\mathrm{T}$ cell proliferation only at a higher concentration of $1000 \mathrm{nM}$ (figure 1D, online supplemental figure S1A). In the next experiments, we applied the dose of $100 \mathrm{nM}$, defined from dose-responses experiments of Src, mTOR and JAK inhibitors conducted in a killing assay using CEA-TCB (online supplemental figure S2-6). Since the effects of MEK1/2 inhibitor trametinib on CEA-TCBmediated cytokine release correlated with an inhibition of tumor cell killing, we did not further investigate this class of kinase inhibitors for the mitigation of CD19-TCB related adverse events (online supplemental figure S2). This work subsequently focused on mTOR and JAK inhibitors in comparison to the effects of the Src inhibitor dasatinib, previously described for TCBs and CAR-T cells. ${ }^{30-33}$

\section{The differential activities of Src, mTOR and JAK inhibitors reveal the uncoupling of CD19-TCB-induced cytokine release and cytotoxicity}

We compared the effects of mTOR and JAK inhibitors to those of Src inhibitors on CD19-TCB-induced T cell activation, cytotoxicity and cytokine release in a killing assay co-culturing CTV-labeled SU-DHL-8 tumor cells with PBMCs and CD19-TCB in the presence and absence of $100 \mathrm{nM}$ of either JAK (ruxolitinib, tofacitinib and baricitinib), mTOR (sirolimus, temsirolimus and everolimus) or Src (dasatinib) inhibitors (figure 2A). As a result, neither the JAK nor the mTOR inhibitors prevented killing of SU-DHL-8 tumor cells, nor $\mathrm{CD}^{+}$and $\mathrm{CD} 8^{+} \mathrm{T}$ cell activation in contrast to the Src inhibitor dasatinib, as indicated by the dose-response curves of dead CTVlabeled SU-DHL-8 cells and the expression of CD69 and $\mathrm{CD} 25$ on $\mathrm{CD}^{+}$and $\mathrm{CD}^{+} \mathrm{T}$ cells (figure $2 \mathrm{~B}, \mathrm{C}$, online supplemental figure S7). Consistently with the switch-off of T cell functionality, the Src inhibitor dasatinib blocked CD19-TCB induced cytokine release (figure 2B-D).
Interestingly, the mTOR inhibitors reduced IFN- $\gamma$, IL-6, granulocyte-macrophage colony-stimulating factor (GMCSF, IL-2 and TNF- $\alpha$ and the JAK inhibitors reduced IFN- $\gamma$, IL-6, GM-CSF and to a lower extent IL-2 and TNF- $\alpha$ (figure 2D). When supplemented on pre-activated PBMCs, sirolimus and ruxolitinib also rapidly suppressed cytokine release while not preventing further killing of CTV-labeled NALM-6 tumor cells, mimicking a clinical intervention for the mitigation of CRS (online supplemental figure S8). In summary, the use of mTOR and JAK inhibitors support the uncoupling of CD19-TCB-induced cytokine release and $\mathrm{T}$ cell cytotoxicity, opening new avenues for the mitigation of CD19-TCB-induced cytokine release.

mTOR and JAK inhibitors suppress CD19-TCB induced cytokine release, comparably to dexamethasone and more robustly than IL-6R and TNF- $\alpha$ blockade with similar effect on $T$-cell cytotoxicity and $T$ cell activation

The effects of mTOR, JAK and Src inhibitors on CD19TCB-induced cytokine release, $\mathrm{T}$ cell activation and tumor cell killing were compared with those of IL-6R blockade and dexamethasone, commonly used in the clinic for the mitigation of CRS, and to TNF- $\alpha$ blockade, currently being explored for the mitigation of CRS. ${ }^{21} 34$ PBMCs were co-cultured with SU-DHL-8 tumor cells and CD19-TCB in the presence and absence of $100 \mathrm{nM}$ of the different kinase inhibitors, $100 \mathrm{nM}$ dexamethasone or $5 \mu \mathrm{g} / \mathrm{mL}$ anti-IL-6R or anti-TNF- $\alpha$. As expected, $100 \mathrm{nM}$ dasatinib completely inhibited SU-DHL-8 tumor cell killing, T cell activation and cytokine release, as opposed to anti-IL-6R, anti-TNF- $\alpha$, dexamethasone and the mTOR and JAK inhibitors which only modulated cytokine release while not strongly affecting tumor cell killing and T cell activation (figure $3 \mathrm{~A}-\mathrm{C}$ ). The mTOR inhibitor sirolimus suppressed CD19-TCB-induced IFN- $\gamma$, TNF- $\alpha$, IL-2 and GM-CSF release to a broader extent than TNF- $\alpha$, IL-6R blockade and ruxolitinib. Indeed, the JAK inhibitor ruxolitinib reduced IFN- $\gamma$ and TNF- $\alpha$ but had a lower effect on IL-2 and GM-CSF release. (figure 3C). Collectively, these data demonstrate that the JAK and mTOR inhibitors more broadly reduce CD19-TCB-induced cytokine secretion than TNF- $\alpha$ or IL-6R blockade while retaining CD19-TCB-mediated tumor cell killing and $\mathrm{T}$ cell activation. Furthermore, mTOR inhibitors appear as preferred candidates to prevent cytokine release while not affecting EC50 values of CD19-TCB-induced SU-DHL-8 tumor cell killing, in contrast to ruxolitinib and dexamethasone (figure 3A).

mTOR and JAK inhibitors suppress CD19-TCB-induced cytokine release in humanized NSG mice while minimally interfering with $B$ cell depletion

To verify if Src, mTOR and JAK inhibitors would suppress CD19-TCB induced cytokine release in vivo, humanized NSG mice were either treated with vehicle or $0.5 \mathrm{mg} / \mathrm{kg}$ CD19-TCB as a monotherapy or combined with sirolimus, ruxolitinib or dasatinib (figure $4 \mathrm{~A}$ ). In parallel, the effect 
A
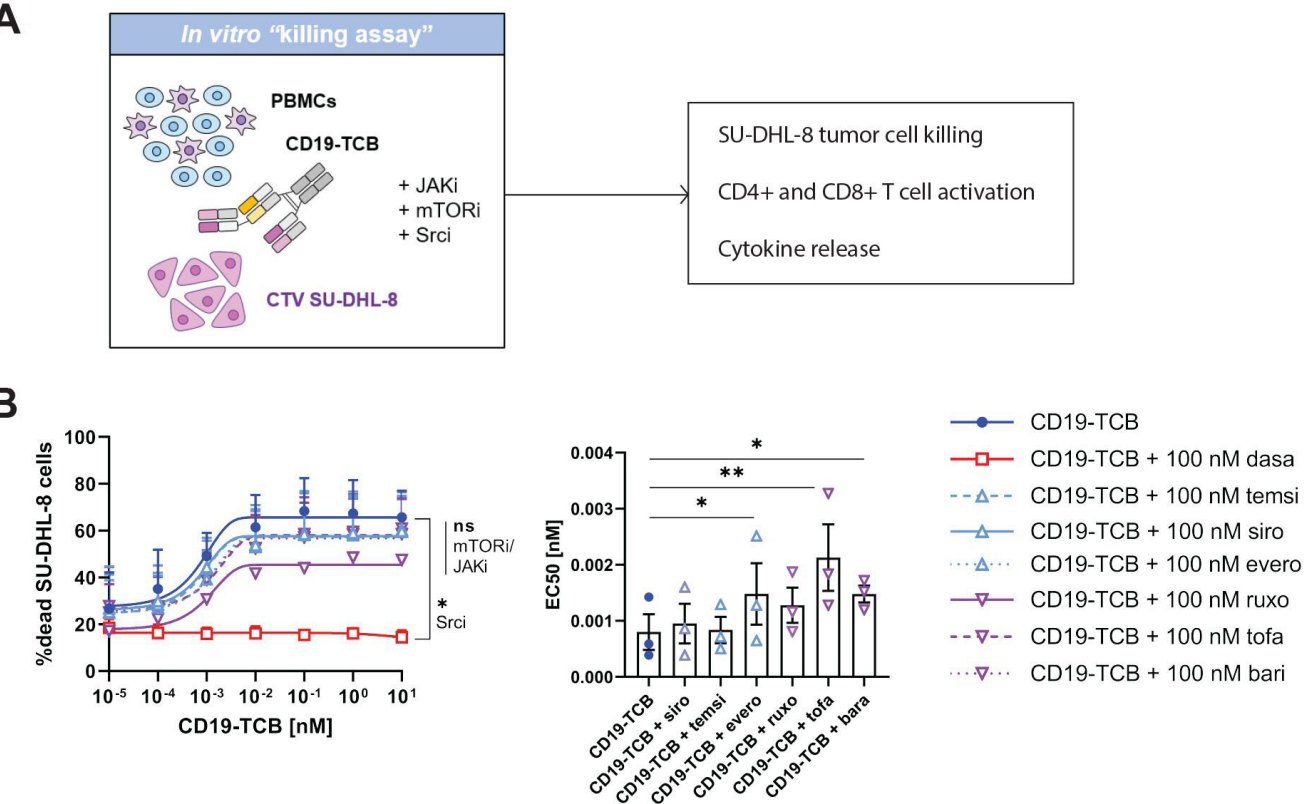

C

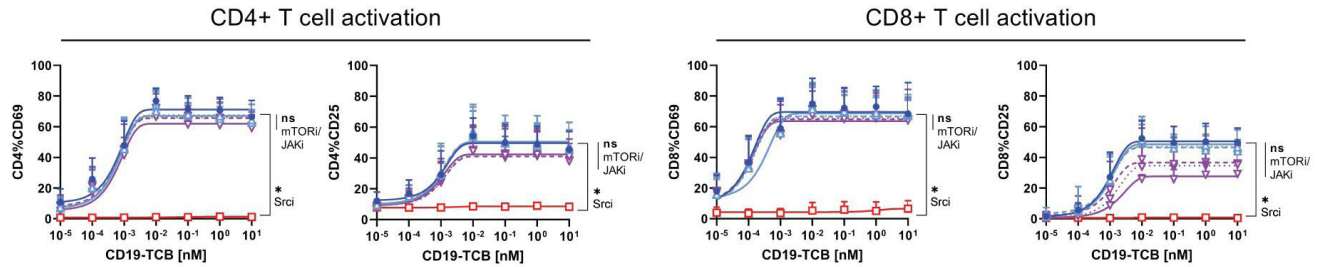

D

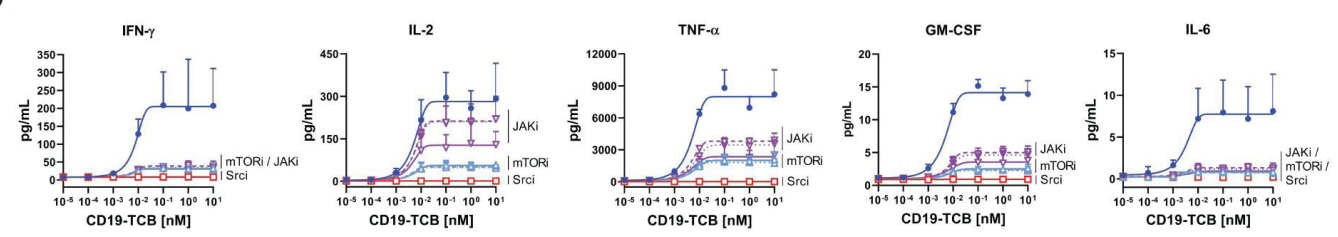

\begin{tabular}{|c|c|c|c|c|c|c|}
\hline & $\begin{array}{l}\text { Kinase } \\
\text { family }\end{array}$ & IFN- $\gamma$ & IL-2 & TNF- $\alpha$ & GM-CSF & IL-6 \\
\hline dasatinib & Src & $* * *$ & $* * *$ & $* * *$ & $* * *$ & $* * *$ \\
\hline sirolimus & \multirow{3}{*}{ mTOR } & ns & * & * & $*$ & ns \\
\hline temsirolimus & & $*$ & $*$ & $*$ & $*$ & $*$ \\
\hline everolimus & & * & $* *$ & $* *$ & $* *$ & $* *$ \\
\hline ruxolitinib & \multirow{3}{*}{ JAK } & * & * & * & * & $*$ \\
\hline tofacitinib & & ns & ns & ns & ns & ns \\
\hline baracitinib & & ns & ns & ns & ns & ns \\
\hline
\end{tabular}

Figure $2 \mathrm{mTOR}$ and JAK but not Src inhibitors prevent CD19-TCB-induced cytokine release while retaining tumor cell killing and T cell activation. (A) PBMCs were stimulated on CTV-labeled SU-DHL-8 tumors cell by CD19-TCB in the presence of SrC inhibitor (dasatinib), mTOR inhibitors (sirolimus, temsirolimus, everolimus) and JAK inhibitors (ruxolitinib, tofacitinib, baricitinib). (B) Effect of JAK, mTOR and Src inhibitors on CD19-TCB-induced killing of SU-DHL-8 tumor cells. At 24 hours, technical replicates were pooled and stained with Live/Dead NIR, allowing measurement of dead SU-DHL-8 cells by flow cytometry by gating on dead NIR positive cells. The EC50 values of each individual killing curve for $n=3$ donors are summarized in the bar plot (except for dasatinib, where EC50 values could not be calculated). (C) The levels of CD69 and CD25 on CD4 ${ }^{+}$and CD8 ${ }^{+} T$ cells induced by CD19-TCB were measured by flow cytometry (24 hours). (B-C) Mean of $n=3$ donors $+S D$ with ${ }^{*} p \leq 0.05$, ${ }^{* *} p \leq 0.01$ by one-way ANOVA (Friedman test). (D) The culture supernatants were pooled and the levels of TNF- $\alpha$, IFN- $\gamma$, IL-2, IL- 6 and GM-CSF were measured by Luminex (24 hours), mean of $n=3$ donors \pm SD. The statistical difference to CD19-TCB treatment are summarized in the table with ${ }^{*} p \leq 0.05,{ }^{* *} p \leq 0.01,{ }^{* \star *} p \leq 0.001$ by one-way ANOVA (Friedman test). ANOVA, analysis of variance; CTV, Cell Trace Violet; GM-CSF, granulocyte-macrophage colony-stimulating factor; IFN, interferon; IL, interleukin; PBMCs, peripheral blood mononuclear cells; TCB, T cell bispecific antibody; TNF, tumor necrosis factor. 
A
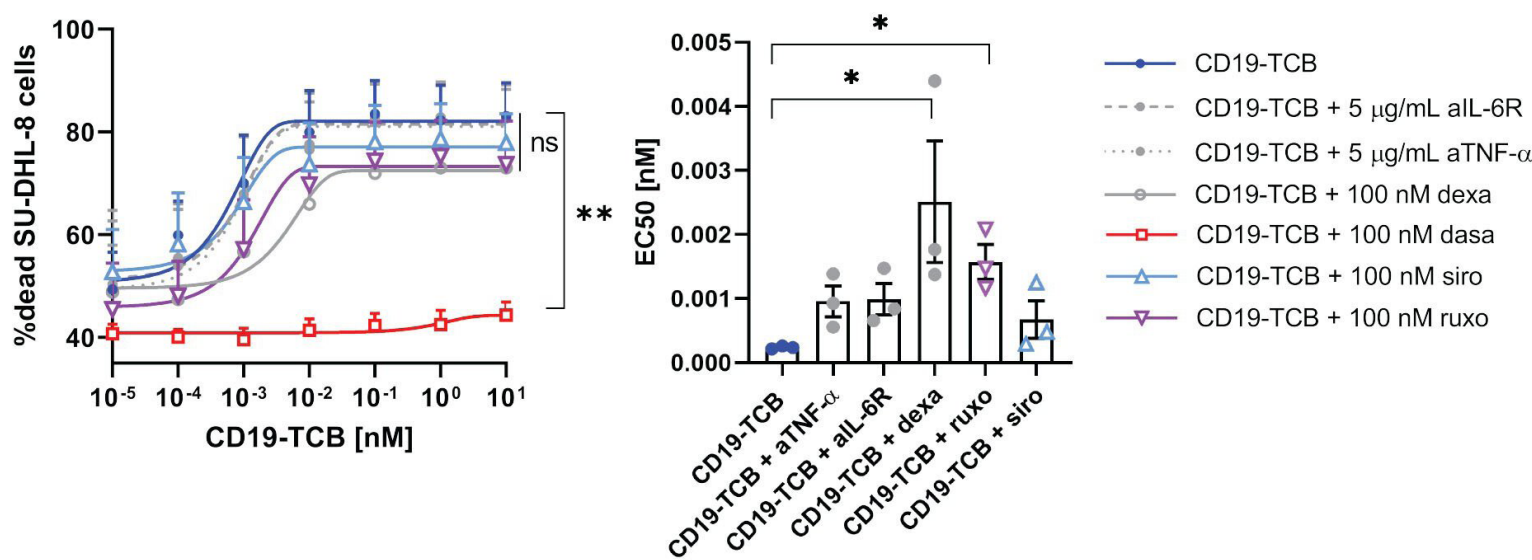

B

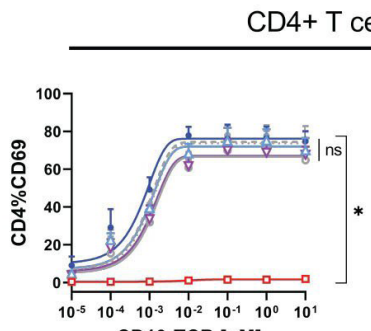

CD19-TCB [nM]

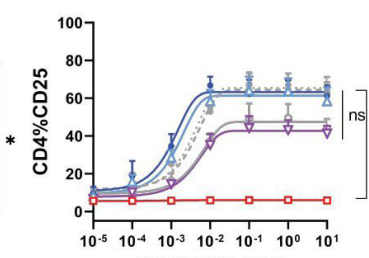

CD19-TCB [nM]

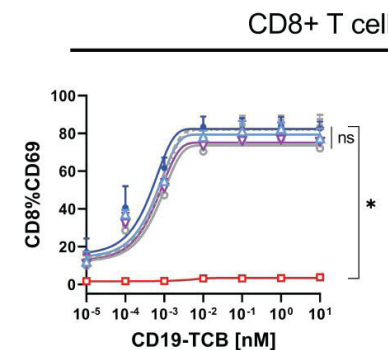

CD19-TCB [nM]

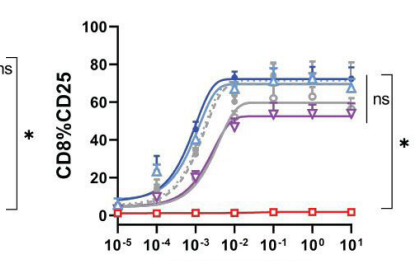

CD19-TCB [nM]

C

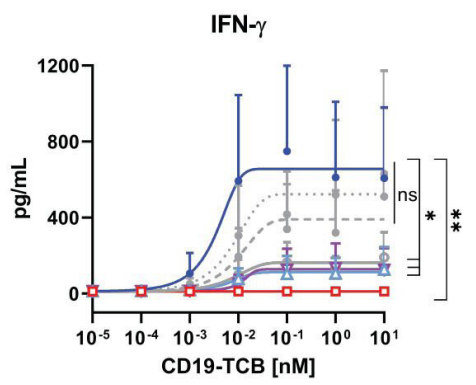

GM-CSF

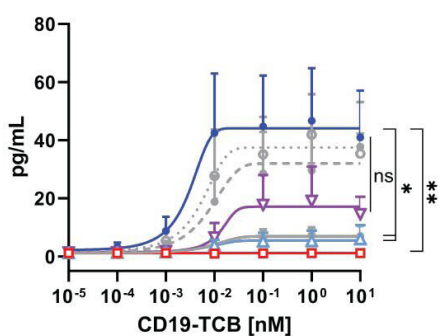

IL-2

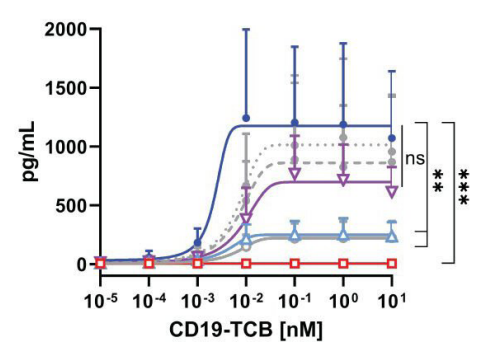

IL-6

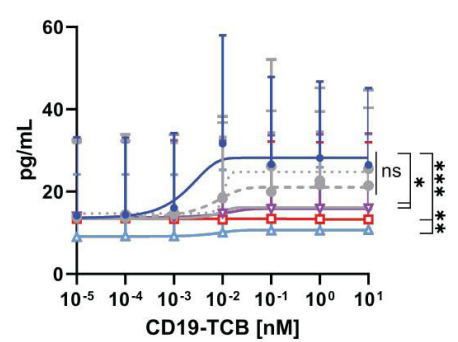

TNF- $\alpha$

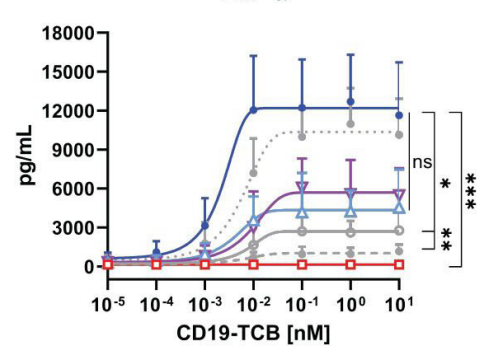

\begin{tabular}{|c|c|c|c|c|c|}
\cline { 2 - 6 } \multicolumn{1}{c|}{} & IFN- $\gamma$ & IL-2 & TNF- $\alpha$ & GM-CSF & IL-6 \\
\hline alL-6R & ns & ns & ns & ns & ns \\
\hline aTNF- $\alpha$ & ns & ns & $* *$ & ns & ns \\
\hline dexa & $* *$ & $* * *$ & $*$ & $*$ & $*$ \\
\hline dasa & $*$ & $* *$ & $* * *$ & $* *$ & $* * *$ \\
\hline siro & $*$ & $* *$ & ns & $*$ & $* *$ \\
\hline ruxo & $*$ & ns & ns & ns & $*$ \\
\hline
\end{tabular}

Figure 3 The effects of mTOR and JAK inhibitors on CD19-TCB induced cytokine release, T cell activation and tumor cell killing are comparable to dexamethasone and more potent than IL-6R and TNF- $\alpha$ blockade in reducing cytokine release. PBMCs were stimulated on CTV labeled SU-DHL-8 tumors cell by CD19-TCB in the presence of $100 \mathrm{nM}$ dasatinib (SrC inhibitor), $100 \mathrm{nM}$ sirolimus (mTOR inhibitor), $100 \mathrm{nM}$ ruxolitinib (JAK inhibitor), $100 \mathrm{nM}$ dexamethasone or $5 \mu \mathrm{g} / \mathrm{mL}$ of anti-IL$6 \mathrm{R}$ or anti-TNF- $\alpha$. (A) At assay endpoint (24 hours), cells from technical replicates were pooled and the killing of CTV-labeled SU-DHL-8 cells was measured by flow cytometry by gating on dead NIR-positive cells. The EC50 values of each individual killing curve for $n=3$ donors are summarized in the bar plot (except for dasatinib, where EC50 values could not be calculated). (B) In addition, the expression of CD69 and CD25 on CD4 ${ }^{+}$and $C D 8^{+} T$ cells was measured by flow cytometry. (C) Finally, the culture supernatants from technical replicates were pooled and the levels of TNF- $\alpha$, IFN- $\gamma$, IL-2 and GM-CSF were measured by Luminex (24 hours). (B-C) Mean of $n=3$ donors \pm SEM with ${ }^{*} \mathrm{p} \leq 0.05,{ }^{* *} \mathrm{p} \leq 0.01,{ }^{* *} \mathrm{p} \leq 0.001$ by one-way analysis of variance (Friedman test). For cytokine data, the statistical differences to CD19-TCB treatment are summarized in the table. CTV, Cell Trace Violet; GM-CSF, granulocyte-macrophage colony-stimulating factor; IFN, interferon; IL, interleukin; PBMCs, peripheral blood mononuclear cells; TCB, T cell bispecific antibody; TNF, tumor necrosis factor. 
A.

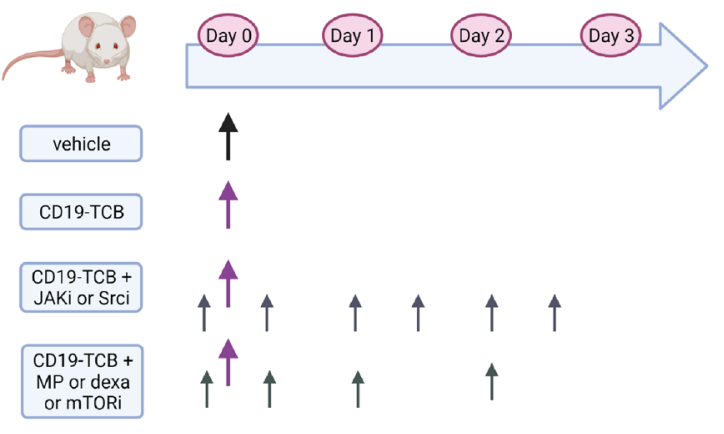

B.

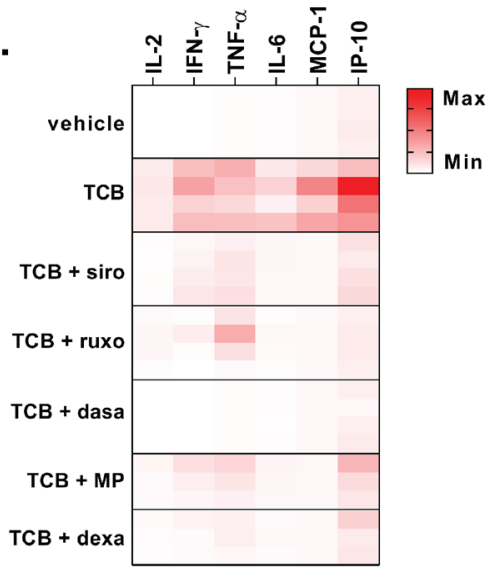

C.

IFN- $\gamma$
IL-2
TNF- $\alpha$

IL-6

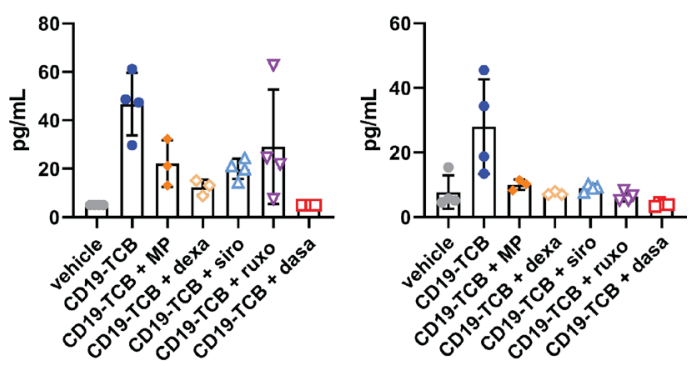

E.

blood - 72 hrs
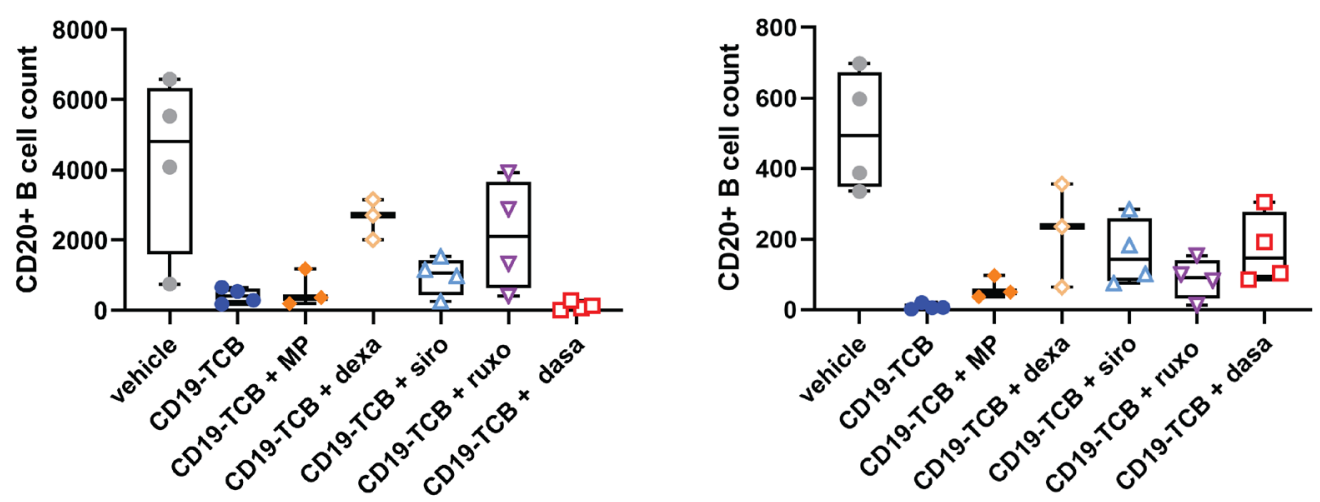

\begin{tabular}{|c|c|c|c|c|c|c|}
\cline { 2 - 7 } \multicolumn{1}{c|}{} & IFN- & TNF- $\boldsymbol{\alpha}$ & IL-2 & IL-6 & $\begin{array}{c}\text { B cell count } \\
\text { (blood) }\end{array}$ & $\begin{array}{c}\text { B cell count } \\
\text { (spleen) }\end{array}$ \\
\hline vehicle & $* *$ & $* * *$ & $* * *$ & $*$ & $* *$ & $*$ \\
\hline CD19-TCB + MP & $\mathrm{ns}(\mathrm{p}>1)$ & $\mathrm{ns}(\mathrm{p}=0.25)$ & $\mathrm{ns}(\mathrm{p}=0.36)$ & $\mathrm{ns}(\mathrm{p}=0.29)$ & $\mathrm{ns}(\mathrm{p}=0.85)$ & $\mathrm{ns}(\mathrm{p}>1)$ \\
\hline $\mathrm{CD} 19-\mathrm{TCB}+$ dexa & $\mathrm{ns}(\mathrm{p}=0.41)$ & $*$ & $\mathrm{~ns}(\mathrm{p}=0.07)$ & $\mathrm{ns}(\mathrm{p}=0.07)$ & $\mathrm{ns}(\mathrm{p}=0.07)$ & $\mathrm{ns}(\mathrm{p}=0.21)$ \\
\hline $\mathrm{CD} 19-\mathrm{TCB}+$ siro & $\mathrm{ns}(\mathrm{p}>1)$ & $\mathrm{ns}(\mathrm{p}=0.17)$ & $*$ & $\mathrm{~ns}(\mathrm{p}=0.21)$ & $\mathrm{ns}(\mathrm{p}=0.45)$ & $\mathrm{ns}(\mathrm{p}=0.27)$ \\
\hline $\mathrm{CD} 19-\mathrm{TCB}+$ ruxo & $*$ & $\mathrm{~ns}(\mathrm{p}=0.33)$ & $\mathrm{ns}(\mathrm{p}=0.20)$ & $* *$ & $\mathrm{~ns}(\mathrm{p}=0.13)$ & $\mathrm{ns}(\mathrm{p}>1)$ \\
\hline $\mathrm{CD} 19-\mathrm{TCB}+$ dasa & $* *$ & $* * *$ & $* * * *$ & $* * * *$ & $\mathrm{~ns}(\mathrm{p}=0.30)$ & $\mathrm{ns}(\mathrm{p}=0.16)$ \\
\hline
\end{tabular}

Figure 4 mTOR and JAK inhibitors mitigate CD19-TCB-induced cytokine release in huNSG mice while not preventing CD19TCB-induced B cell depletion. (A) In vivo experiment timelines and dosing schedule. Humanized NSG mice were co-treated with $0.5 \mathrm{mg} / \mathrm{kg}$ CD19-TCB (intravenously) alone or in combination with $50 \mathrm{mg} / \mathrm{kg}$ dasatinib (p.o.), $30 \mathrm{mg} / \mathrm{kg}$ ruxolitinib (p.o), $5 \mathrm{mg} / \mathrm{kg}$ sirolimus (p.o.), two times $1 \mathrm{mg} / \mathrm{kg}, 0.5 \mathrm{mg} / \mathrm{kg}$ and $0.25 \mathrm{mg} / \mathrm{kg}$ dexamethasone (p.o), or two times $10 \mathrm{mg} / \mathrm{kg}, 5 \mathrm{mg} / \mathrm{kg}, 2.5 \mathrm{mg} / \mathrm{kg}$ methylprednisolone (p.o.). Figure made with BioRender.com. (B, C) Serum was collected from blood 6 hours post infusion with CD19-TCB and cytokine levels were measured by Luminex. The cytokine levels for each mouse were either compared across different treatment groups in a heat map or shown as mean of individual values (bar plots). (D, E). The counts of CD20 B cells were measured in the spleen and blood collected at termination (72 hours) to assess the effect of kinase inhibitors on CD19TCB-dependent B cell depletion. (C-E) The statistical differences to CD19-TCB monotherapy treatment are summarized in the table. Mean of $n=4$ or 3 mice $\pm S D$ with ${ }^{*} p \leq 0.05,{ }^{* *} p \leq 0.01,{ }^{* * *} p \leq 0.001,{ }^{* * * *} p \leq 0.0001$ by one-way analysis of variance (KruskalWallis test). IFN, interferon; IL, interleukin; IP, interferon gamma-induced protein MP, methylprednisolone; MCP, monocyte chemoattractant protein; p.o., orally; TCB, T cell bispecific antibody; TNF, tumor necrosis factor. 
of dexamethasone and methylprednisolone were also evaluated in this model. The different kinase inhibitors and glucocorticoids were given orally to reproduce the clinical route of administration. As a result, the mTOR inhibitor sirolimus reduced the levels of IFN- $\gamma$, IL-2, IL-6 and TNF- $\alpha$ on infusion with CD19-TCB, comparably to dexamethasone, methylprednisolone and less efficiently than dasatinib (figure $4 \mathrm{~B}, \mathrm{C}$ ). In line with in vitro observations, the JAK inhibitor ruxolitinib preferentially reduced IFN- $\gamma$ and IL-6 with a milder effect on TNF- $\alpha$ and IL-2 release (figure 4B,C). Additionally, the other JAK inhibitor baricitinib behaved like ruxolitinib and the other mTOR inhibitors temsirolimus and everolimus like sirolimus in reducing CD19-TCB-induced cytokine release (online supplemental figure S9). Importantly, the CD20 ${ }^{+}$ B cell counts measured in the spleen and peripheral blood (72hours) at study termination showed that sirolimus and ruxolitinib induced a moderate, yet not significant, inhibitory effect on CD19-TCB-mediated B cell depletion (figure 4D,E). Dasatinib did not fully block CD19-TCB activity as indicated by the $\mathrm{CD} 20^{+} \mathrm{B}$ cell counts measured 72 hours after CD19-TCB administration, consistent with our recent findings showing that dasatinib switches-off CD19-TCB activity up to 48 hours on treatment with CD19-TCB (figure 4D,E) ${ }^{32} 33$

Overall, this experiment demonstrates that the pharmacodynamic profile of mTOR and JAK inhibitors in vivo is favorable to control CD19-TCB-mediated cytokine release, comparably to dexamethasone or methylprednisolone and less pronounced than dasatinib. In line with previous in vitro findings, mTOR inhibitors more broadly reduced cytokine release than JAK inhibitors. When applied continuously during 3 days, the different kinase inhibitors only minimally reduced CD19-TCB-mediated cytotoxicity, suggesting that transient treatment for the mitigation of CRS should not impair antitumor efficacy.

\section{mTOR and JAK inhibitors do not suppress CD19-TCB antitumor activity in lymphoma PDX bearing mice, similarly to dexamethasone}

We then evaluated the impact of Src, mTOR and JAK inhibition in comparison to dexamethasone on CD19-TCB antitumor activity in humanized NSG mice engrafted with a lymphoma PDX. In vitro, these lymphoma cells were efficiently depleted by CD19-TCB in a killing assay (online supplemental figure S10). Mice bearing established PDX tumors were treated with either vehicle, CD19-TCB as a monotherapy or sirolimus, ruxolitinib, dasatinib, dexamethasone alone or in combination with CD19-TCB (online supplemental figure S11A). The different kinase inhibitors and dexamethasone were given 1 hour prior to the first treatment with CD19-TCB and subsequently once or twice per day for 3 days to prevent cytokine release, predominantly occurring on the first infusion. Moreover, they were also administered 1 hour before each subsequent treatment to prevent eventual residual cytokine secretion (online supplemental figure S11A). Both, dexamethasone and sirolimus, given as a single agent, induced a reduction in tumor growth, yet not significant (figure 5A,D). When combined with CD19-TCB, the resulting antitumor efficacy was slightly but not significantly reduced and no reduction of $\mathrm{T}$ cell infiltration in the tumors was observed (figure 5A, D and E). However, sirolimus and dexamethasone suppressed IL-2, IFN- $\gamma$, TNF- $\alpha$ and IL- 6 release on the first infusion (figure 5F). Additionally, co-treatment with ruxolitinib minimally interfered with CD19-TCB antitumor activity and T cell infiltration in the tumor and decreased IL- 6 and to a lower extent IFN- $\gamma$, TNF- $\alpha$ and IL-2 release (figure 5B, E and F). Lastly, dasatinib strongly reduced T-cell derived cytokines (IFN- $\gamma$, TNF- $\alpha$ and IL-2) on the first infusion while moderately affecting CD19-TCB antitumor efficacy and $\mathrm{T}$ cell infiltration (figure $5 \mathrm{C}, \mathrm{E}$ and $\mathrm{F}$ ). Yet, this effect was not significant (figure 5C). This indicates that the transient use of dasatinib did not continuously block CD19-TCB-induced $\mathrm{T}$ cell cytotoxicity, in agreement with the reversible inhibitory properties of dasatinib. ${ }^{32} 33$ Additionally, cytokine levels were much lower 6 hours on the second infusion of CD19-TCB, suggesting that treatment with kinase inhibitors on the first infusion should be sufficient to prevent cytokine release (online supplemental figure S12).

In summary, the transient use of ruxolitinib and sirolimus, similarly to dexamethasone, decreased T-cell mediated cytokine release on the first infusion of CD19-TCB, resulting in a better safety profile as indicated by the overall survival curves and changes in body weight (online supplemental figure S11B,C). Importantly, ruxolitinib, sirolimus and dexamethasone had comparable effects on CD19-TCB-induced antitumor efficacy (online supplemental figure S11D).

\section{mTOR, JAK and Src inhibitors prevent rapid exhaustion of T cells after prolonged exposure to CD19-TCB}

To further investigate how JAK, Src and mTOR inhibitors may retain the efficacy of CD19-TCB, we assessed their effect on $\mathrm{T}$ cell exhaustion after prolonged exposure to CD19-TCB using PD1, TIM3 and LAG3 as surrogate readouts. For this purpose, PBMCs were co-cultured with SU-DHL-8 tumor cells and CD19-TCB in the presence and absence of $100 \mathrm{nM}$ of JAK, mTOR and Src kinase inhibitors for 5 days. As a result, the Src inhibitor dasatinib stopped $\mathrm{T}$ cell exhaustion, as indicated by the low expression of PD1, TIM3 and LAG3 on $\mathrm{CD}^{+}$and $\mathrm{CD} 8^{+}$ $\mathrm{T}$ cells (figure 6A,B). Furthermore, the JAK inhibitor ruxolitinib and mTOR inhibitor sirolimus reduced the expression of these three markers on $\mathrm{T}$ cells compared with CD19-TCB alone, suggesting that they may minimize rapid $T$ cell exhaustion after treatment with CD19-TCB (figure 6A,B). Altogether, these data suggest that the Src inhibitor dasatinib and, to some extent, the JAK (ruxolitinib) and mTOR (sirolimus) inhibitors may protect $\mathrm{T}$ cells from rapid exhaustion after continuous stimulation with CD19-TCB, and prolong their functionality in addition to preventing cytokine release. 
A

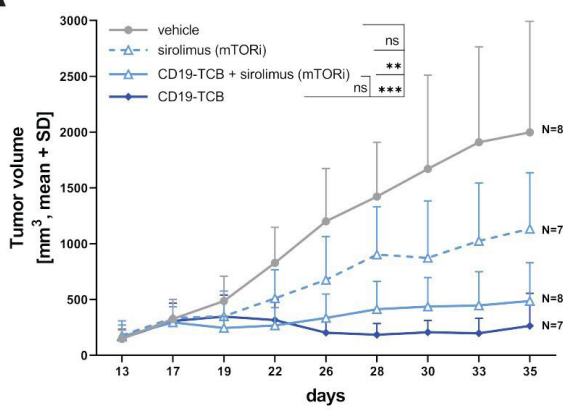

C

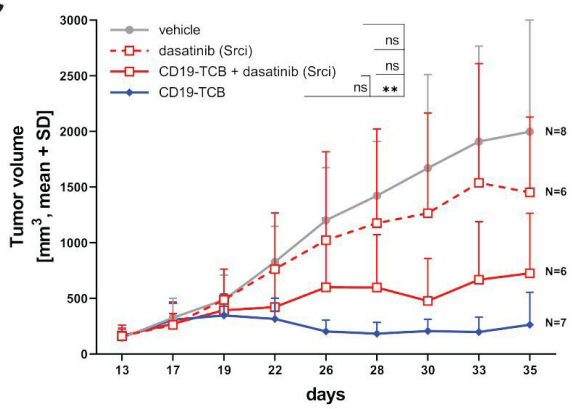

B
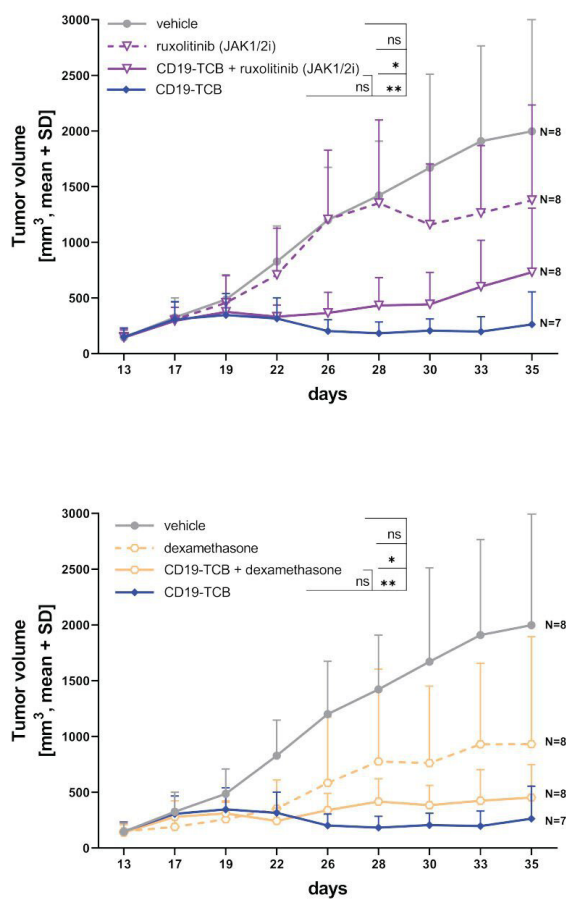

E

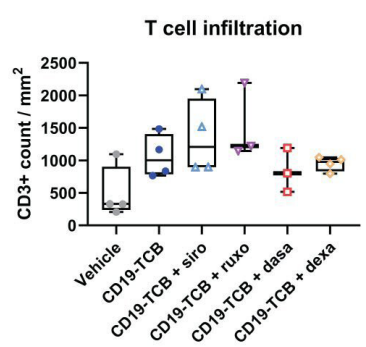

$\mathbf{F}$

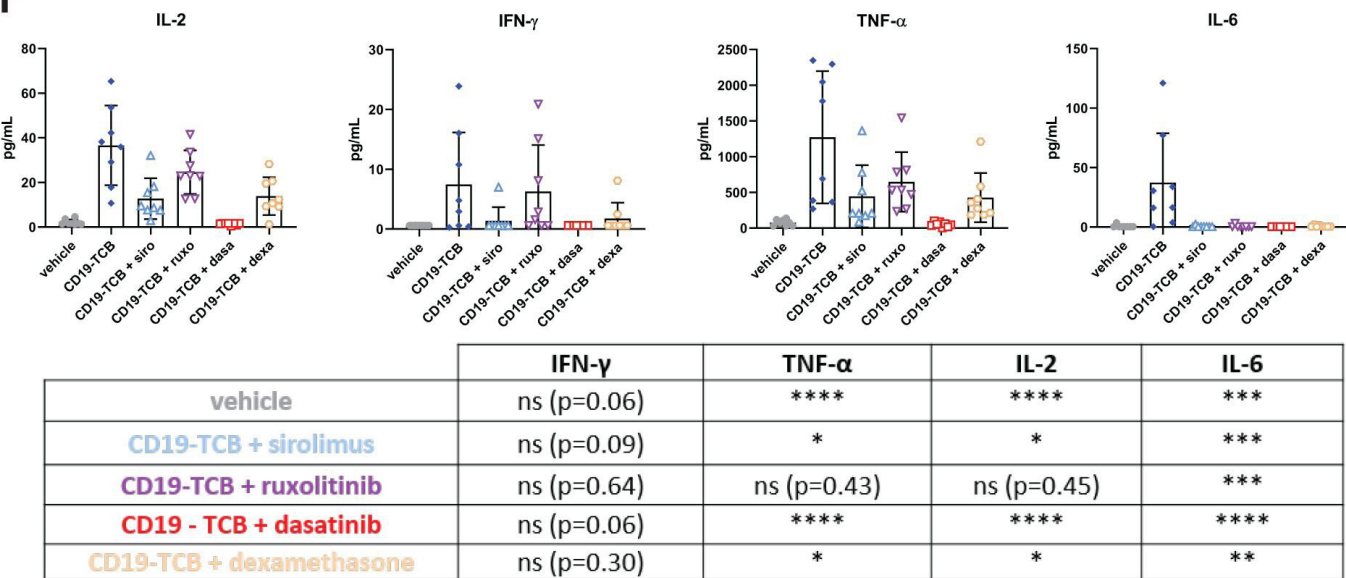

Figure 5 mTOR and JAK inhibitors do not inhibit CD19-TCB antitumor efficacy in vivo. Humanized NSG mice were engrafted with a lymphoma PDX (5 million cells, s.c.). When tumors reached $200 \mathrm{~mm}^{3}$, mice were randomized in groups of eight or seven based on their tumor size. They were treated with vehicle (intravenously), $5 \mathrm{mg} / \mathrm{kg}$ sirolimus (p.o.), $30 \mathrm{mg} / \mathrm{kg}$ ruxolitinib (p.o.), $20 \mathrm{mg} / \mathrm{kg}$ dasatinib (p.o.), two times $1 \mathrm{mg} / \mathrm{kg}, 0.5 \mathrm{mg} / \mathrm{kg}$, four times $0.25 \mathrm{mg} / \mathrm{kg}$ dexamethasone (p.o.) alone or in combination with $0.5 \mathrm{mg} / \mathrm{kg}$ CD19-TCB (intravenously), $0.5 \mathrm{mg} / \mathrm{kg}$ CD19-TCB (intravenously) as a monotherapy. (A-D) Tumor growth curves were plotted from tumor volumes measured using a Caliper, mean of $n=6-8$ mice+SD with ${ }^{*} p \leq 0.05,{ }^{* \star} p \leq 0.01,{ }^{* \star *} p \leq 0.001$ by one-way ANOVA (Kruskal-Wallis test). (E) Trends of CD3 counts in the tumors at experiment termination. Tumor sections were immunohistochemically stained with anti-CD3 (brown) and nuclei were counterstained with hematoxylin. $\mathrm{CD}^{+}{ }^{+} \mathrm{T}$ cells were quantified in the different sections with the Visiopharm software. (F) The levels of IL-2, IFN- $\gamma$, IL-6 and TNF- $\alpha$ in the serum of the mice collected 6 hours post first infusion with CD19-TCB. The statistical differences to CD19-TCB treatment are summarized in the table. Mean of $n=6-8$ mice+SD with ${ }^{*} p \leq 0.05,{ }^{* *} p \leq 0.01,{ }^{* *} p \leq 0.001$ by one-way ANOVA (Kruskal-Wallis test). ANOVA, analysis of variance; IFN, interferon; IL, interleukin; PDX, patient-derived xenograft; s.c., subcutaneously; p.o., orally; TCB, T cell bispecific antibody; TNF, tumor necrosis factor. 

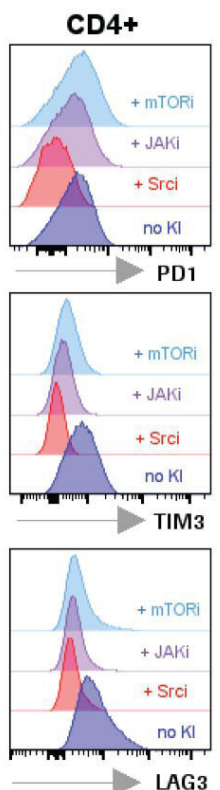

CD8+
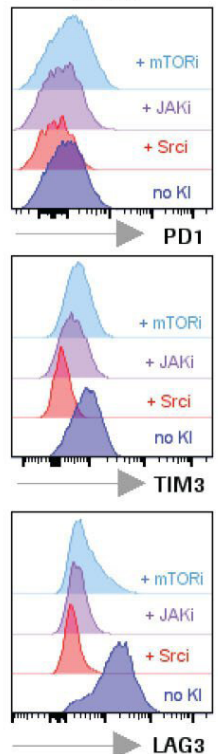

CD4+
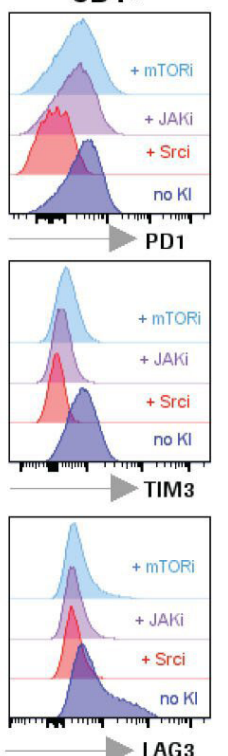

CD8+
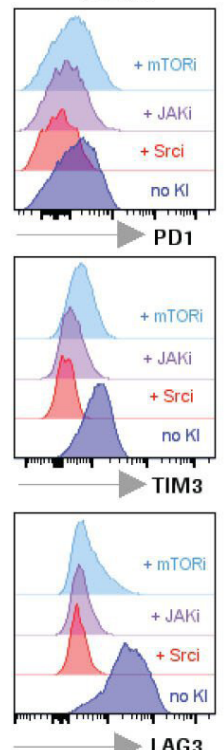

CD4+
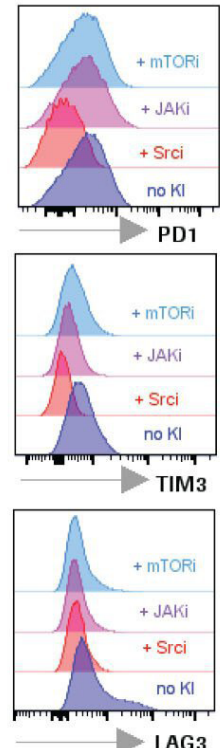

B
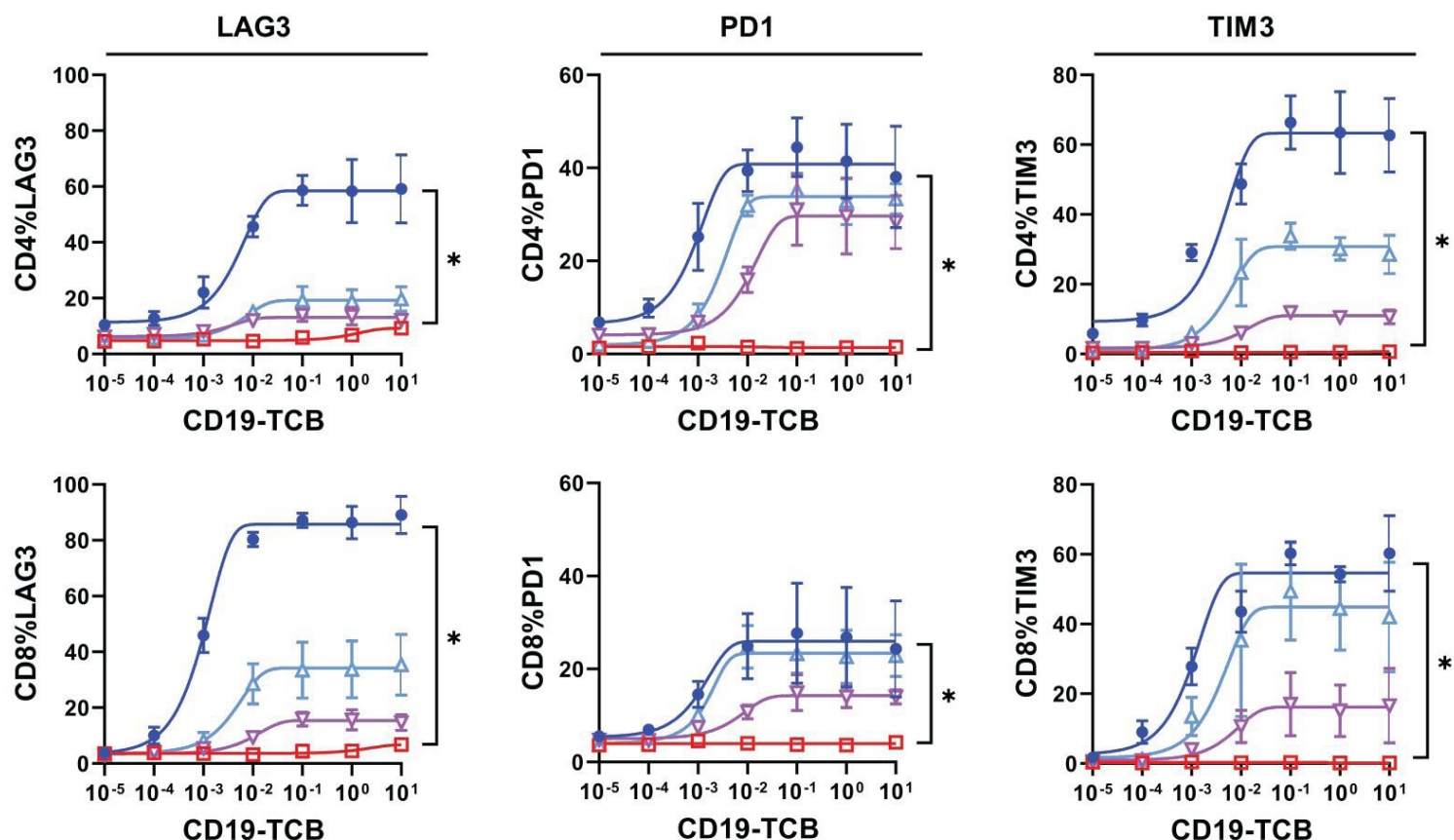

CD19-TCB

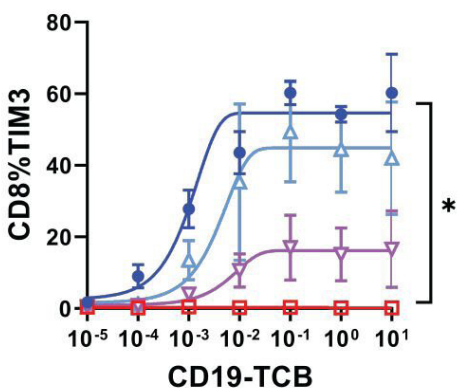

$$
\begin{aligned}
& \rightarrow \text { CD19-TCB } \\
& \because \text { CD19-TCB + } 100 \text { nM dasa } \\
& \rightarrow \text { CD19-TCB + } 100 \text { nM ruxo } \\
& -\triangle \text { CD19-TCB + } 100 \text { nM siro }
\end{aligned}
$$

Figure 6 Effect of Src, JAK and mTOR kinase inhibitors on T cell exhaustion induced by prolonged treatment with CD19TCB. PBMCs co-cultured with SU-DHL-8 tumors cell were stimulated by CD19-TCB in the presence of $100 \mathrm{nM}$ dasatinib (Src inhibitor), $100 \mathrm{nM}$ sirolimus (mTOR inhibitor) or $100 \mathrm{nM}$ ruxolitinib (JAK inhibitor) for 5 days. Cells from technical duplicates were pooled and the expression of PD1, TIM3 and LAG3 on CD4 ${ }^{+}$and CD8 ${ }^{+}$was measured by flow cytometry. (A) Histogram plots showing the effects of $100 \mathrm{nM}$ dasatinib (Srci), $100 \mathrm{nM}$ sirolimus (mTORi) and $100 \mathrm{nM}$ ruxolitinib (JAKi) on the expression of PD1, TIM3 and LAG3 induced by $10 \mathrm{nM}$ CD19-TCB for $n=3$ donors. (B) The dose-response curves show the effect of kinase inhibitors on PD1, TIM3 and LAG3 expression on $\mathrm{CD}^{+}$and $\mathrm{CD} 8^{+} \mathrm{T}$ cells, means of $\mathrm{n}=3$ donors $\pm \mathrm{SD}$ with * $\mathrm{p} \leq 0.05$ by one-way analysis of variance (Kruskal-Wallis test). LAG3, lymphocyte-activation gene 3; PBMCs, peripheral blood mononuclear cells; PD1, programmed cell death protein-1; TCB, T cell bispecific antibody; TIM3, T cell immunoglobulin and mucin-domain 3. 
Table 1 In vitro effective doses of ruxolitinib, sirolimus, everolimus, temsirolimus and dasatinib as well as their respective clinical dose(s) and corresponding exposure(s)

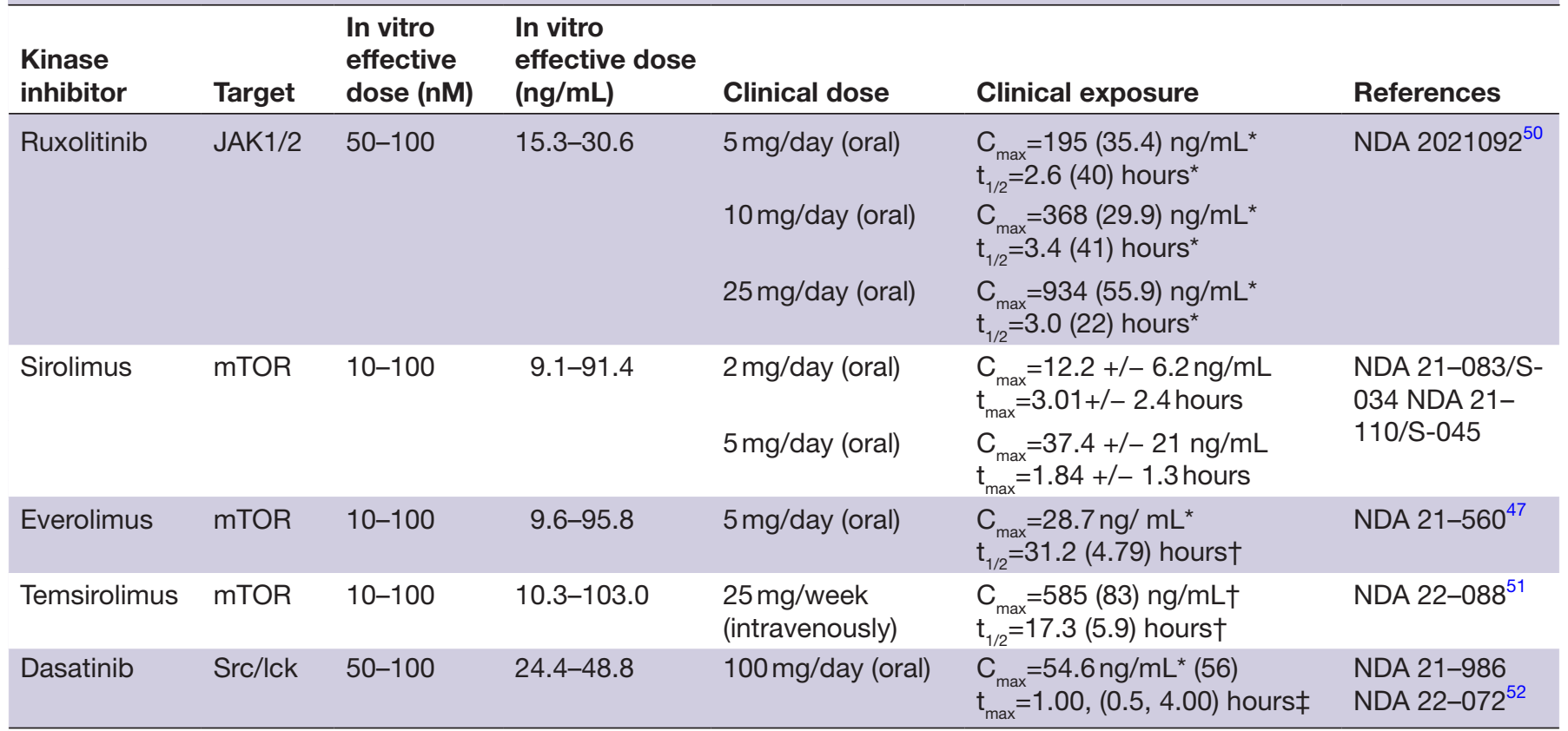

${ }^{*}$ Geometric mean (per cent coefficient of variation (\%)).

†Mean (SD).

$\ddagger$ Median (min, max).

\section{DISCUSSION}

By screening a library of 52 FDA-approved kinase inhibitors for their impact on $\mathrm{T}$ cell proliferation and cytokine release after $\mathrm{CD} 3$ stimulation, we identified mTOR, JAK and Src kinases inhibitors as potential candidates to modulate TCB-mediated cytokine release at pharmacologically active doses, as indicated in table 1 . The effects of Src inhibitors differed from those of JAK and mTOR inhibitors with the suppression of CD19-TCB-induced tumor cell lysis in vitro (online supplemental figure S13). In contrast, JAK and mTOR inhibitors, comparably to dexamethasone, did not have a major impact on $\mathrm{T}$ cell killing and more broadly reduced TCB-mediated cytokine release than anti-TNF- $\alpha$ or anti-IL-6R antibodies (online supplemental figure S13). Of note, mTOR inhibitors did not affect EC50 values of killing curves on CD19-TCB treatment, suggesting that they might be the preferred candidates over dexamethasone and JAK inhibitors for the prophylactic mitigation of CRS after treatment with TCBs. Importantly, JAK, mTOR and Src inhibitors also prevented cytokine release from PBMCs previously activated by a TCB. When used as intervention treatment for CRS, it is reasonable to think that kinase inhibitors would not only prevent release of T-cell derived cytokines but also-as a downstream consequence of the former-myeloid cell-derived cytokines known to be the key mediators of CRS. ${ }^{20-22} 3536$ The in vitro co-culture of human PBMCs and tumor cells might be a better tool to recapitulate the effects of kinase inhibitors on myeloid cell-derived cytokines (IL-6, IL-1 $\beta$ and TNF- $\alpha$ ) than the in vivo humanized mouse model that is limited in the proportion of myeloid cells. In non-tumor bearing humanized NSG mice, the combination of pharmacokinetic/pharmacodynamic $(\mathrm{PK} / \mathrm{PD})$ properties of small molecules kinase inhibitors and CD19-TCB favorably reduced cytokine release on the first infusion, with comparable effects as glucocorticoids. In lymphoma PDX-bearing humanized NSG mice, transient treatment with Src, mTOR and JAK inhibitors on the first infusion inhibited cytokine release while minimally impairing CD19-TCB antitumor efficacy, comparably to dexamethasone. ${ }^{37}{ }^{38}$ Glucocorticoids and anti-IL-6R antibodies are the standard of care for the management of CRS, with only a small percentage of patients being refractory and requiring alternative treatments. Nevertheless, CRS remains the main dose limiting toxicity for T-cell engaging therapies, and the requirement for prompt intervention to manage higher grade CRS prevents these therapies from achieving broader uptake. Therefore combination strategies to reduce the occurrence of CRS and increase or sustain treatment efficacy, as described by Bacac et al with the use of obinutuzumab pretreatment and CD20-TCB, remain to be investigated for other indications. ${ }^{6}$ Altogether, our data emphasizes that prophylactic treatment with kinase inhibitors would not impair the long-term antitumor efficacy of TCBs and may even prevent rapid T cell exhaustion after prolonged exposure to TCB, similar to the findings recently reported for dasatinib in the context of CAR-T cell therapy. ${ }^{39}$

Since the complex biology of CRS involves many more cytokines than the described TNF- $\alpha$, IL- 6 , IFN- $\gamma$ and IL-1 $\beta$, JAK inhibitors blocking inflammatory pathways, such as 
the JAK/STAT pathway, may have superior efficacy than selective antagonistic antibodies specifically blocking IL-6/IL-6R, TNF- $\alpha$, GM-CSF or IL-1 $\beta .^{21-23} 344041$ In line with preclinical findings from Kenderian et al showing that ruxolitinib prevented CD123-CAR-T cell induced cytokine release in vivo and with findings from Huarte et al demonstrating that ruxolitinib prevented the cytokine storm in models of hyperinflammation, our data confirm that JAK inhibitors prevented TCB inducedcytokine release, however, less efficiently than mTOR or Src inhibitors. ${ }^{41}{ }^{42}$ Indeed, they retained the release of IL-2, GM-CSF and only partially suppressed the release of TNF- $\alpha$, suggesting that a combination with an anti-TNF- $\alpha$ antibody may be advantageous for the management of TCB-induced cytokine release. This approach was used to manage grade 3 CRS in two patients treated with CAR-T cell against $\mathrm{CD} 7^{+} \mathrm{T}$ lymphocytes. ${ }^{43}$ In line with this, Uy $e t$ al reported that prophylactic treatment with ruxolitinib decreased cytokine secretion, but did not lead to discernable improvement in clinical severity of CRS in patients receiving flotetuzumab, emphasizing that ruxolitinib alone may not be sufficient to suppress CRS. ${ }^{44}$ Itacitinib, a more selective JAK1 inhibitor, is being explored for the prevention of CD19-CAR-T cell induced CRS in patients with hematological malignancies. ${ }^{35} 45$

Dasatinib appears less attractive than JAK, mTOR inhibitors or dexamethasone for the mitigation of TCBmediated cytokine release since it fully suppresses $\mathrm{T}$ cell cytotoxicity in vitro. The intervention with dasatinib was initially developed as a potential safety trigger switching off T-cell cytotoxicity in case of severe CRS or on-target offtumor activity mediated by CAR-T cells or $\mathrm{T}$ cell engagers where a rapid $\mathrm{T}$ cell switch-off would be not be achieved with glucocorticoids ${ }^{29-33}$. Yet, the in vivo inhibitory effects of dasatinib differed from those observed in vitro. In vivo, it was difficult to achieve a continuous exposure required to stop CD19-TCB-induced $\mathrm{T}$ cell activation, due to the short PK/PD profile of dasatinib. Moreover, the inhibitory properties of dasatinib being reversible, CD19-TCB could again activate $\mathrm{T}$ cells when dasatinib exposure became insufficient. Uninterrupted administrations of dasatinib before and after treatment with CD19-TCB were shown to switch-off cytokine release and B-cell depletion for up to 48 hours. Nevertheless, short treatment interventions with dasatinib on first and subsequent CD19-TCB administrations in mice engrafted with a lymphoma PDX minimally interfered with antitumor efficacy, while fully switching-off cytokine release more profoundly than JAK, mTOR inhibitors or glucocorticoids. Thus, dasatinib may be used transiently as prophylaxis medication to prevent CRS on first infusion with TCB. Additionally, Foà et al showed that the use of dasatinib as induction therapy in patients with Philadelphia chromosome positive leukemia followed by a consolidation therapy with concomitant treatment of blinatumomab and dasatinib was safe and efficacious. ${ }^{46}$ Dasatinib could prevent exhausted the $\mathrm{T}$ cell phenotype induced by CD19-TCB treatment, which may result in extending the functionality of T cells. Along those lines, recent findings from Weber et al demonstrated that reversible ON/OFF switches with dasatinib prevent CAR-T cell exhaustion and improve their longterm functionality. ${ }^{39}$ Last, Leclercq et al have shown that dasatinib more strongly reduced $\mathrm{CD} 4^{+} \mathrm{T}$ cell than $\mathrm{CD} 8^{+} \mathrm{T}$ cell proliferation when added on pre-stimulated $\mathrm{T}$ cells, suggesting that dasatinib may retain $\mathrm{CD} 8^{+} \mathrm{T}$ cell effector functions when used transiently in vivo. ${ }^{33}$

For the first time, we described the use of mTOR inhibitors sirolimus, temsirolimus and everolimus to block TCB-induced cytokine release. Based on the in vitro comparison, mTOR inhibitors appear to be the most potent inhibitors to strongly reduce cytokine release while not interfering with $\mathrm{T}$ cell killing. In vivo, the effect of sirolimus favorably prevented CD19-TCB-mediated cytokine release while retaining efficacy with comparable effect to JAK, Src inhibitors and dexamethasone. Altogether, this suggests that mTOR inhibitors may be the preferred candidates for prophylaxis of CRS. Since mTOR inhibitors are used as antitumor agents in various solid cancers, a combination with a TCB to prevent CRS while maintaining efficacy may be of particular interest in such indications. ${ }^{478}$ In line with this, for a patient with melanoma who underwent kidney allograft rejection while receiving pembrolizumab, Esfahani et al showed that sirolimus did not interfere with pembrolizumab-mediated antitumor activity while preventing organ rejection. ${ }^{49}$ Additionally, mTOR reduced the expression of exhaustion markers on $\mathrm{T}$ cells induced by CD19-TCB, which may result in extending their functionality. This further supports the mTOR pathways as a target to mitigate inflammationdriven adverse events related to treatment with immunotherapies while retaining their efficacy. Taken together, these preclinical data support the further investigation of mTOR, Src and JAK inhibitors for the prophylaxis of $\mathrm{T}$ cell induced cytokine release after treatment with TCBs as well as their on-treatment effects on the functionality of $\mathrm{T}$ cells.

Acknowledgements The authors thank all the members of the CD19-TCB and CEA-TCB team for reviewing the article as well as all members from Cancer Immunotherapy, Oncology, Large Molecule Research, and Pharmaceutical Sciences at Roche Pharmaceutical Research and Early Development (pRED) who contributed to the development of these programs; Oncology DTA, Pharmaceutical Science and pRED leadership for their support during all phases of this project.

Contributors Concept and Experimental design: GL, HH, VP, AT, LG, TZ, NS, JS, MB, CK. Acquisition of data: GL, TZ. Data analysis and interpretation: GL, TZ, AT, LG, HH, AS, AMG, VP, JS, NS, MB, MS, CK. Writing, review and/or revision of the manuscript: GL, HH, AT, CK, MB, AS, A0, MS. Administrative, technical or material support: JC, TZ, AF-G, LL. Guarantor: GL. Study supervision: CK, HH, AS, AMG, MB, PU.

Funding All funding for the studies were provided by Roche. The authors do not declare a specific grant for this research from any funding agency in the public, commercial or not-for-profit sectors.

Competing interests $\mathrm{GL}, \mathrm{HH}, \mathrm{CK}, \mathrm{AT}$, and $\mathrm{TZ}$ declare patent applications related to the work described. All authors, except A0, are employees of Roche or were employed by Roche at the time of this study. All the authors, except A0, GL and NS declare ownership of Roche stock. All funding for the studies were provided by Roche. The authors do not declare a specific grant for this research from any funding agency in the public, commercial or not-for-profit sectors. 


\section{Patient consent for publication Not applicable.}

Ethics approval The in vivo work on mice was conducted in accordance with the Swiss Animal Protection Law and under the AAALAC accreditation.

Provenance and peer review Not commissioned; externally peer reviewed.

Data availability statement Data are available upon reasonable request.

Supplemental material This content has been supplied by the author(s). It has not been vetted by BMJ Publishing Group Limited (BMJ) and may not have been peer-reviewed. Any opinions or recommendations discussed are solely those of the author(s) and are not endorsed by BMJ. BMJ disclaims all liability and responsibility arising from any reliance placed on the content. Where the content includes any translated material, BMJ does not warrant the accuracy and reliability of the translations (including but not limited to local regulations, clinical guidelines, terminology, drug names and drug dosages), and is not responsible for any error and/or omissions arising from translation and adaptation or otherwise.

Open access This is an open access article distributed in accordance with the Creative Commons Attribution Non Commercial (CC BY-NC 4.0) license, which permits others to distribute, remix, adapt, build upon this work non-commercially, and license their derivative works on different terms, provided the original work is properly cited, appropriate credit is given, any changes made indicated, and the use is non-commercial. See http://creativecommons.org/licenses/by-nc/4.0/.

\section{ORCID iDs}

Gabrielle Leclercq http://orcid.org/0000-0003-0576-0546

Alex Odermatt http://orcid.org/0000-0002-6820-2712

Christian Klein http://orcid.org/0000-0001-7594-7280

\section{REFERENCES}

1 Goebeler M-E, Bargou RC. T cell-engaging therapies - BiTEs and beyond. Nat Rev Clin Oncol 2020.

2 Singh A, Dees S, Grewal IS. Overcoming the challenges associated with $\mathrm{CD} 3+\mathrm{T}$-cell redirection in cancer. $\mathrm{Br} \mathrm{J}$ Cancer 2021;124:1037-48.

3 Crawford A, Chiu D. Targeting solid tumors using CD3 bispecific antibodies. Mol Cancer Ther 2021;20:molcanther.0073.2021.

4 Bacac M, Fauti T, Sam J, et al. A novel carcinoembryonic antigen Tcell bispecific antibody (CEA TCB) for the treatment of solid tumors. Clin Cancer Res 2016:22:3286-97.

5 Bacac M, Klein C, Umana P. CEA TCB: a novel head-to-tail 2:1 T cell bispecific antibody for treatment of CEA-positive solid tumors. Oncoimmunology 2016;5:e1203498.

6 Bacac M, Colombetti S, Herter S, et al. CD20-TCB with obinutuzumab pretreatment as next-generation treatment of hematologic malignancies. Clin Cancer Res 2018;24:4785-97.

7 Goebeler M-E, Bargou RC. T cell-engaging therapies - BiTEs and beyond. Nat Rev Clin Oncol 2020;17:418-34.

8 Einsele H, Borghaei H, Orlowski RZ, et al. The BiTE (bispecific T-cell engager) platform: development and future potential of a targeted immuno-oncology therapy across tumor types. Cancer 2020;126:3192-201.

9 Clynes RA, Desjarlais JR. Redirected T cell cytotoxicity in cancer therapy. Annu Rev Med 2019;70:437-50.

10 Ellerman D. Bispecific T-cell engagers: towards understanding variables influencing the in vitro potency and tumor selectivity and their modulation to enhance their efficacy and safety. Methods 2019;154:102-17.

11 Labrijn AF, Janmaat ML, Reichert JM, et al. Bispecific antibodies: a mechanistic review of the pipeline. Nat Rev Drug Discov 2019;18:585-608.

12 Carter PJ, Lazar GA. Next generation antibody drugs: pursuit of the 'high-hanging fruit'. Nat Rev Drug Discov 2018;17:197-223.

13 Wu Z, Cheung NV, Wu Z. T cell engaging bispecific antibody (T-BsAb): from technology to therapeutics. Pharmacol Ther 2018;182:161-75.

14 Klein C, Schaefer W, Regula JT. The use of CrossMAb technology for the generation of bi- and multispecific antibodies. MAbs 2016;8:1010-20.

15 Schlothauer T, Herter S, Koller CF, et al. Novel human IgG1 and IgG4 Fc-engineered antibodies with completely abolished immune effector functions. Protein Eng Des Sel 2016;29:457-66.

16 Hinrichs CS, Restifo NP. Reassessing target antigens for adoptive T-cell therapy. Nat Biotechnol 2013;31:999-1008.

17 Shimabukuro-Vornhagen A, Gödel P, Subklewe M, et al. Cytokine release syndrome. J Immunother Cancer 2018;6:56.
18 Riegler LL, Jones GP, Lee DW. Current approaches in the grading and management of cytokine release syndrome after chimeric antigen receptor T-cell therapy. Ther Clin Risk Manag 2019;15:323-35.

19 Liu D, Zhao J. Cytokine release syndrome: grading, modeling, and new therapy. J Hematol Oncol 2018;11:121.

20 Godbersen-Palmer C, Coupet TA, Grada Z, et al. Toxicity induced by a bispecific $T$ cell-redirecting protein is mediated by both $T$ cells and myeloid cells in immunocompetent mice. J Immunol 2020;204:2973-83.

21 Li J, Piskol R, Ybarra R, et al. CD3 bispecific antibody-induced cytokine release is dispensable for cytotoxic T cell activity. Sci Transl Med 2019;11:1. doi:10.1126/scitranslmed.aax8861

22 Giavridis T, van der Stegen SJC, Eyquem J, et al. CAR T cell-induced cytokine release syndrome is mediated by macrophages and abated by IL-1 blockade. Nat Med 2018;24:731-8. doi:10.1038/s41591-0180041-7

23 Norelli M, Camisa B, Barbiera G, et al. Monocyte-derived IL-1 and IL-6 are differentially required for cytokine-release syndrome and neurotoxicity due to CAR T cells. Nat Med 2018;24:739-48.

24 Lee DW, Santomasso BD, Locke FL, et al. ASTCT consensus grading for cytokine release syndrome and neurologic toxicity associated with immune effector cells. Biol Blood Marrow Transplant 2019;25:625-38.

25 Teachey DT, Rheingold SR, Maude SL, et al. Cytokine release syndrome after blinatumomab treatment related to abnormal macrophage activation and ameliorated with cytokine-directed therapy. Blood 2013;121:5154-7.

26 Neelapu SS, Tummala S, Kebriaei P, et al. Chimeric antigen receptor T-cell therapy - assessment and management of toxicities. Nat Rev Clin Oncol 2018;15:47-62.

27 Roskoski R. Properties of FDA-approved small molecule protein kinase inhibitors: a 2020 update. Pharmacol Res 2020;152:104609.

28 Blake S, Hughes TP, Mayrhofer G, et al. The Src/ABL kinase inhibitor dasatinib (BMS-354825) inhibits function of normal human Tlymphocytes in vitro. Clin Immunol 2008;127:330-9.

29 Leonard JT, Kosaka Y, Malla P, et al. Concomitant use of a dual Src/ ABL kinase inhibitor eliminates the in vitro efficacy of blinatumomab against Ph+ ALL. Blood 2021;137:939-44.

30 Mestermann K, Giavridis T, Weber J, et al. The tyrosine kinase inhibitor dasatinib acts as a pharmacologic on/off switch for CAR T cells. Sci Transl Med 2019;11:eaau5907.

31 Weber EW, Lynn RC, Sotillo E, et al. Pharmacologic control of CAR-T cell function using dasatinib. Blood Adv 2019;3:711-7.

32 Leclercq G, Haegel H, Schneider A, et al. 653 Dasatinib as a rapid pharmacological ON/OFF switch for T cell bispecific antibodyinduced T cell activation and cytokine release. $J$ Immunother Cancer 2020;8:A690. doi:10.1136/jitc-2020-SITC2020.0653

33 Leclercq G, Haegel H, Schneider A, et al. Src/lck inhibitor dasatinib reversibly switches off cytokine release and $\mathrm{T}$ cell cytotoxicity following stimulation with T cell bispecific antibodies. J Immunother Cancer 2021;9:e002582.

34 Zhang L, Wang S, Xu J, et al. Etanercept as a new therapeutic option for cytokine release syndrome following chimeric antigen receptor $T$ cell therapy. Exp Hematol Oncol 2021;10:16.

35 Huarte E, O'Connor RS, Peel MT, et al. Itacitinib (INCB039110), a JAK1 inhibitor, reduces cytokines associated with cytokine release syndrome induced by car T-cell therapy. Clin Cancer Res 2020;26:6299-309.

36 Hao Z, Li R, Meng L, et al. Macrophage, the potential key mediator in CAR-T related CRS. Exp Hematol Oncol 2020;9:15.

37 Liu S, Deng B, Yin Z, et al. Corticosteroids do not influence the efficacy and kinetics of CAR-T cells for B-cell acute lymphoblastic leukemia. Blood Cancer J 2020;10:15.

38 Mori S, Nelson RJ, Patel RD, et al. Low dose steroids can alleviate blinatumomab-associated toxicities without negatively impacting treatment efficacy. Blood 2015;126:4875.

39 Weber EW, Parker KR, Sotillo E, et al. Transient rest restores functionality in exhausted CAR-T cells through epigenetic remodeling. Science 2021;372 doi:10.1126/science.aba1786

40 Sterner RM, Sakemura R, Cox MJ, et al. GM-CSF inhibition reduces cytokine release syndrome and neuroinflammation but enhances CAR-T cell function in xenografts. Blood 2019;133:697-709.

41 Huarte E, Peel MT, Verbist K, et al. Ruxolitinib, a JAK1/2 inhibitor, ameliorates cytokine storm in experimental models of Hyperinflammation syndrome. Front Pharmacol 2021;12:650295.

42 Kenderian SS, Ruella M, Shestova O, et al. Ruxolitinib prevents cytokine release syndrome after car T-cell therapy without impairing the anti-tumor effect in a xenograft model. Biology of Blood and Marrow Transplantation 2017;23:S19-20. doi:10.1016/j. bbmt.2016.12.003 
43 Li S, Wang X, Yuan Z, et al. Eradication of T-ALL cells by CD7targeted universal CAR-T cells and initial test of Ruxolitinib-based CRS management. Clin Cancer Res 2021;27:1242-6.

44 GL U, Rettig MP, Christ S. Prophylactic ruxolitinib for cytokine release syndrome (CRS) in relapse/refractory (R/R) AML patients treated with flotetuzumab. Blood 2020;136:19-21.

45 Park JH, Frigault MJ, Maziarz RT, et al. Trial in progress: a phase 2 , single-arm, open-label study of Itacitinib (ITA) for the prevention of chimeric antigen receptor (CAR) T-Cell-Induced cytokine release syndrome (CRS). Biology Blood Marrow Transplant 2020;26:S269.

46 Foà R, Bassan R, Vitale A, et al. Dasatinib-blinatumomab for Ph-positive acute lymphoblastic leukemia in adults. N Engl $\mathrm{J}$ Med 2020;383:1613-23.

47 Thudium K, Gallo J, Bouillaud E, et al. Bioavailability of everolimus administered as a single $5 \mathrm{mg}$ tablet versus five $1 \mathrm{mg}$ tablets: a randomized, open-label, two-way crossover study of healthy volunteers. Clin Pharmacol 2015;7:11-17.
48 Xu T, Sun D, Chen Y, et al. Targeting mTOR for fighting diseases: a revisited review of mTOR inhibitors. Eur J Med Chem 2020;199:112391.

49 Esfahani K, Al-Aubodah T-A, Thebault P, et al. Targeting the mTOR pathway uncouples the efficacy and toxicity of PD-1 blockade in renal transplantation. Nat Commun 2019;10:4712.

50 Shi JG, Chen X, McGee RF, et al. The pharmacokinetics, pharmacodynamics, and safety of orally dosed INCB018424 phosphate in healthy volunteers. $J$ Clin Pharmacol 2011:51:1644-54.

51 Boni JP, Hug B, Leister C, et al. Intravenous temsirolimus in cancer patients: clinical pharmacology and dosing considerations. Semin Oncol 2009;36:S18-25.

52 Wang X, Roy A, Hochhaus A, et al. Differential effects of dosing regimen on the safety and efficacy of dasatinib: retrospective exposure-response analysis of a phase III study. Clin Pharmacol 2013;5:85-97. 